NBER WORKING PAPER SERIES

\title{
IMMIGRATION AND REGIONAL SPECIALIZATION IN AI
}

\author{
Gordon H. Hanson \\ Working Paper 28671 \\ http://www.nber.org/papers/w28671 \\ NATIONAL BUREAU OF ECONOMIC RESEARCH \\ 1050 Massachusetts Avenue \\ Cambridge, MA 02138 \\ April 2021
}

I thank Savannah Noray for excellent research assistance. The views expressed herein are those of the author and do not necessarily reflect the views of the National Bureau of Economic Research.

NBER working papers are circulated for discussion and comment purposes. They have not been peer-reviewed or been subject to the review by the NBER Board of Directors that accompanies official NBER publications.

(C) 2021 by Gordon H. Hanson. All rights reserved. Short sections of text, not to exceed two paragraphs, may be quoted without explicit permission provided that full credit, including (C) notice, is given to the source. 
Immigration and Regional Specialization in AI

Gordon H. Hanson

NBER Working Paper No. 28671

April 2021

JEL No. J61,R12

\begin{abstract}
$\underline{\text { ABSTRACT }}$
I examine the specialization of US commuting zones in AI-related occupations over the 2000 to 2018 period. I define AI-related jobs based on keywords in Census occupational titles. Using the approach in Lin (2011) to identify new work, I measure job growth related to AI by weighting employment growth in AI-related occupations by the share of job titles in these occupations that were added after 1990. Overall, regional specialization in AI-related activities mirrors that of regional specialization in IT. However, foreign-born and native-born workers within the sector tend to cluster in different locations. Whereas specialization of the foreign-born in AI-related jobs is strongest in high-tech hubs with a preponderance of private-sector employment, native-born specialization in AI-related jobs is strongest in centers for military and space-related research. Nationally, foreign-born workers account for $55 \%$ of job growth in AI-related occupations since 2000. In regression analysis, I find that US commuting zones exposed to a larger increases in the supply of college-educated immigrants became more specialized in AI-related occupations and that this increased specialization was due entirely to the employment of the foreign born. My results suggest that access to highly skilled workers constrains AI-related job growth and that immigration of the college-educated helps relax this constraint.
\end{abstract}

Gordon H. Hanson

Harvard Kennedy School

Harvard University

79 John F. Kennedy St.

Cambridge, MA 02138

and NBER

gordon_hanson@hks.harvard.edu 


\section{Introduction}

There is immense academic and policy interest in how artificial intelligence (AI) will affect labor markets. Given the disruptive impacts of technological change on earnings and employment in recent decades, such interest is understandable. The rapid pace of skillbiased technical change after 1980 is credited with raising the earnings premia for workers with college degrees (Katz \& Autor, 1999), which contributed to greater income inequality in many high-income countries. Amid these changes, the automation of routine tasks shifted employment away from middle-skill jobs, leaving a more hollowed-out earnings distribution in its wake (Autor \& Dorn, 2013; Goos et al., 2014). The expanding use of industrial robots (Acemoglu \& Restrepo, 2020) and employment of contract workers via Uber-like platforms (Abraham et al., 2019; Chen et al., 2019) are the most recent ways in which new technology is upending the world of work. With the potential for AI to convert many job tasks into algorithmic routines that can be performed by machines, yet another wave of disruption may be on the horizon (Autor et al., 2020).

In this paper, I turn my attention not to the labor-market consequences of AI but to the forces governing where AI itself is being created. Three innovations have helped make AI possible (Varian, 2018). One is new approaches to machine learning, another is advances in high-speed and special-purpose computing, and a third is the proliferation of very large data sets in digital format. Machine learning combines techniques from statistics and computer science to predict outcomes or learn patterns from raw data. When embedded in a system that feeds in data, applies domain expertise, and governs learning, AI is created (Taddy, 2018). This process requires teams of computer scientists, data scientists, engineers, network systems analysts, and programmers, as well as workers with knowledge of the domains in which AI will operate. The need for high-speed computing arises from the non-linearity and high dimensionality of prediction models, which require large data sets for training, validation, and testing. Of the key inputs to AI, it is the final stage of machine learning and systems engineering that appears to be the most location specific. Creating AI involves computer hardware manufactured elsewhere, data collected from disparate sources, and teams of specialists who tend to work in close proximity.

If AI comes anywhere close to its forecasted potential, there will be an enormous market for AI-related goods and services. Just as employment in new technology tends to be highly geographically concentrated (Moretti, 2012, 2019; Bloom et al., 2020), it is natural to expect AI-related activities to exhibit strong patterns of spatial agglomeration. Understanding emerging comparative advantage in jobs related to $\mathrm{AI}$ is therefore important for evaluating how the technology will change national and global trade patterns. Trade in 
AI-related services is poorly measured, both because it is new and because revenue flows from trade in technology services are hard to detect in conventional data. To study what comparative advantage in the production of AI might look like, I take US commuting zones as my unit of analysis (Tolbert \& Sizer, 1996). A regional focus allows me to measure comparative advantage via abundantly available employment data rather than via poorly documented trade flows. Because the US is at the frontier of innovations in AI and IT, it is where regional comparative advantage in new technology is likely to manifest itself first. Even with this focus, the newness of AI creates measurement challenges. I study the occupations that appear to encompass AI-related activities, recognizing that such categories will also include jobs in IT that do not necessarily involve AI. The analysis is therefore subject to the maintained hypothesis that the spatial allocation of employment in AI will resemble that in non-AI jobs that require AI-like skills.

My aim is to understand regional changes in US AI-related employment over the last two decades. Although machine learning dates to the 1950s (Cockburn et al., 2018), the field did not begin to flourish until the 1990s. It was not until after 2000, and especially after 2010, that it came into widespread use (Taddy, 2018). The first step in the analysis is to identify occupations likely to be involved in the production of AI. Within occupations associated with STEM disciplines, I select the occupational codes that are likely to contain AI-producing jobs based on their associated Census-defined job titles having at least one term from each of the two following sets: computer, data, or software; and design/designer, engineer, research/researcher, or science/scientist. This procedure identifies 30 occupational titles, out of 707 total titles in the broader STEM category, as being AI-related. The selected job titles include, for example, "artificial intelligence specialist" and "information scientist." Using a wider filter identifies 146 AI-related titles. Because employment can be measured at the occupational code but not at the title level, I focus on the codes that contain these titles. Within these codes, I use results in Lin (2011) to identify the occupational titles that were created after 1990, which is when advances in AI began to accelerate. Following his work, I interpret new job titles as evidence of the creation of new types of work. ${ }^{1}$ The creation of new work in AI-related occupations is a signal of AI-related innovations in employment. To measure employment growth in AI jobs over 2000 to 2018, I weight employment growth in AI-related occupations over the period by the share of job titles within an occupation that were new as of 2000. By varying the restrictiveness of the filters used to define AI-related jobs, I check the robustness of the findings to the definition of AI-related activities.

\footnotetext{
${ }^{1}$ For literature that examines the creation of new work across all occupations and over longer time spans, see Atalay et al. (2020) and Autor et al. (2020).
} 
An alternative way to measure employment in AI would be to use job postings that explicitly mention the application of artificial intelligence. A rapidly emerging literature takes this approach to examine changes in labor-market outcomes for the occupations that appear likely to be disrupted by AI (see, e.g., Brynjolfsson et al., 2018; Felten et al., 2018; Acemoglu et al., 2020; Bloom et al., 2020; Webb, 2020). Less work is devoted to figuring out which jobs are involved the creation of $\mathrm{AI}$ and its applications. Acemoglu et al. (2020) use job-posting data from Burning Glass to measure the expansion of jobs in AI-producing activities. The advantage of these data is that job postings contain explicit mention of skills related to AI (e.g., computer vision, deep learning, machine learning). ${ }^{2}$ Disadvantages include job postings being unavailable in complete form until 2010 and a lack of information on the ultimate number of hires that result from postings. My focus on employment growth in AI-related jobs since 2000 explains my choice to define AI-related occupations using the the Census Bureau list of occupational titles.

The second step in the analysis is to examine regional specialization in AI-related occupations. Two patterns stand out in the data. One is that regional specialization in AIrelated jobs is greatest in commuting zones that became hubs for technology jobs in the 1980s or 1990s. These CZs include Austin, Boston, Oakland, San Jose, Seattle, and Washington, DC. Their specialization in AI-related occupations was already substantial in 2000 and became more substantial still by 2018 . These are the same cities in which high-tech startups and patenting in high-tech domains are also concentrated (Chatterji et al., 2014; Moretti, 2019). A second pattern is that increased specialization in AI-related jobs in techoriented CZs is due primarily to the employment of foreign-born men. Whereas the CZs in which native-born workers are most concentrated in AI-related jobs include cities specialized in government-funded military research (Colorado Springs, CO; Alexandria, VA) and space research (Melbourne, FL; Huntsville, AL), those in which foreign-born men are most concentrated in AI-related fields account for the largest AI employment clusters and are the ones in which private firms dominate the high-tech landscape. Looking across the origin countries of these foreign-born workers, there is wide variation in revealed comparative advantage in AI-related jobs. Comparative advantage in AI-related occupations is strongest for workers born in East and South Asia and weakest for workers born in Latin America and the Caribbean and the US. Although women account for a relatively small share of employment in AI-related occupations, their revealed comparative advantage in AI by country of birth is similar to that for men.

It is well known that across occupations specialization varies among foreign-born

\footnotetext{
${ }^{2}$ Bloom et al. (2020) develop a conceptually related approach to identify new technology by tracking the presence of key words or phrases in company earnings calls and Burning Glass job postings.
} 
workers by their country of origin and that immigrants from specific countries tend to concentrate in specific US cities (see, e.g., Patel \& Vella 2013; Hanson \& Liu 2017; Burstein et al. 2020). These regularities are also manifest in the case of AI-related activities. Because the skills required to create artificial intelligence and related innovations in information technology are scarce and because some countries seem better than others at producing workers capable of acquiring the required skills, the regions that are best positioned to attract high-skilled foreign-born workers appear to be the ones most likely acquire comparative advantage in AI. Over the period 2000 to 2018, foreign-born workers accounted for $54.6 \%$ of the increase in hours worked in AI-related activities.

The third step in the analysis is to identify the factors behind regional employment growth in AI-related jobs. Motivated by the importance of highly educated foreign-born workers in AI-related employment, I model changes in regional specialization in AI as a function of the change in college-educated immigrant labor supply confronting each region. I estimate the change in the $\mathrm{CZ}$ share of employment of prime-age college-educated workers in AI-related occupations over the 2000 to 2018 period as a function of the projected local increase in college-educated immigrants. Inspired by the shift-share approach of Altonji \& Card (1991) and Card (2001), I predict the increase in the supply of collegeeducated immigrants in a $\mathrm{CZ}$ using national growth in college-educated immigrants from each origin country (outside of the CZ) and the initial-period share of the CZ in the employment of college-educated immigrants from each origin country (outside of AI-related jobs). For men, the immigrant supply shock is strongly positively correlated with employment growth in AI-related occupations. This effect comes entirely from increased employment of the foreign born. The impact of the immigrant labor-supply shock on the employment of native-born men is small and imprecisely estimated, indicating that arriving foreign-born workers neither crowd-in nor crowd-out the native-born in AI-related activities. Results are similar for the employment of women in AI-related occupations, though coefficient magnitudes are smaller, consistent with relatively weaker specialization in AI-related jobs on the part of foreign-born females. I find similar results whether using worker counts or hours worked to measure employment and whether using a narrow or a broad definition of AI-related occupations.

Whereas in earlier decades computer power and data availability were binding constraints on the advance of AI, today those constraints seem closer to being slack. The binding constraint is more likely to be on the supply of workers sufficiently skilled to design the computing architecture, devise the learning algorithms, apply the domain science, and construct the business systems necessary to create AI. Not surprisingly, building successful teams involves a global search for talent (Hanson \& Slaughter, 2018). My 
results suggest that the US regions that are best positioned to attract foreign talent are those that are acquiring a stronger comparative advantage in AI-related activities. Three important actors in the global talent search are the US government, which regulates the supply of visas to high-skilled immigrants (Lazear, 2021); US universities, which admit many future US foreign-born tech workers as students (Bound et al., 2017, 2021); and US technology companies, whose recruitment strategies also help bring skilled foreign workers to the US (Kerr \& Lincoln, 2010). The interdependent choices of these actors create a business ecosystem in which innovation in AI has been able to flourish. However, it does not appear to be the only ecosystem that is conducive to such innovation. To create AI, China is taking a more state-directed approach, including trade protection for domestic technology firms (Goldfarb \& Trefler, 2018), and is relying mostly on domestic talent. In terms of academic journal publications and awarded patents, its approach has had some success (Xie \& Freeman, 2020). When it comes to projecting my results to the world as a whole, one needs to address how these different ecosystems will fare in global competition with each other, a subject on which my analysis is silent.

The empirical results connect to several bodies of literature. A first is analysis of the labor market consequences of regional labor-supply shocks related to immigration. My finding that arriving immigrant workers neither crowd in nor crowd out native-born workers in AI-related jobs is consistent with results in Burstein et al. (2020) across all occupations dedicated to tradable activities. ${ }^{3}$ Because arriving immigrant workers can be absorbed into the production of exports (i.e., AI routines), they need not displace existing native-born workers. A second body of related work addresses the occupational comparative advantage of immigrants. Foreign-born workers from non-English-speaking countries tend to avoid jobs that are intensive in communication-based tasks (Dustmann \& Fabbri, 2003; Peri \& Sparber, 2009; Oreopoulos, 2011), and to specialize STEM fields (Hunt \& Gauthier-Loiselle, 2010), especially those related to computing and engineering (Hunt, 2015). Specialization in STEM may account for the over-representation of the foreign-born among US inventors (Kerr \& Lincoln, 2010; Hunt, 2011; Bernstein et al., 2018) and for the positive correlation between growth in college-educated immigrant labor supply and regional productivity growth (Peri et al., 2015). The concentration of foreign-born workers in AI-related activities is the latest manifestation of the propensity for immigrant labor to specialize in technology-oriented fields in the US labor market.

My analysis does not address why immigrants with skills applicable to AI are drawn to the US. The concentration of leading IT firms in the US is one explanation for the at-

\footnotetext{
${ }^{3}$ See Borjas \& Doran (2012) for evidence on how arriving Russian mathematicians displaced US scholars working in subfields in mathematics in which Soviet-era research was relatively specialized.
} 
traction. Another is that the highly educated are drawn to the US because it offers rewards to skill that are large relative to other high-income destination countries (Grogger \& Hanson, 2011). Nor does my work account for why workers from particular countries appear to excel in AI fields. Hanson \& Liu (2021) find that immigrants specializing in jobs more intensive in abstract and quantitative reasoning tend to come from countries that deliver higher-quality K-12 education, as evidenced by their students achieving higher PISA exam scores. Similar forces may be at work regarding specialization in AI. It is also unclear whether the specialization of foreign-born workers in AI will translate into a comparative advantage in AI in their countries of origin. Whereas China is both a major source of AI talent to the US labor market and the home to leading AI firms, India checks the first box but not the second (at least as far as conventional data reveal). By implication, the presence of firms with core capabilities in computing (or protection from foreign firms with such capabilities) may be necessary for AI to develop.

In Section 2, I describe how I measure AI-related employment; in Section 3, I present descriptive evidence on specialization in AI-related jobs across US commuting zones; in Section 4, I present empirical analysis of how immigrant labor-supply shocks affect regional employment in AI-related occupations; and in Section 5, I conclude.

\section{Measuring Employment in AI-Related Occupations}

Artificial intelligence distinguishes itself by requiring technical skills in computer science, engineering, math, and related disciplines, and by being new (or at least new at a scale to become detectable by employment surveys). My approach to measuring employment in AI-related occupations keys on both of these features: the technical definitions of occupations and their newness. Of course, new work in AI-related fields may include new work in IT that is not exclusive to AI. I therefore refer to my measures as capturing growth in "AI-related" jobs rather than in jobs that are solely dedicated to AI.

\subsection{Defining AI-Related Occupational Categories}

The Census Bureau defines occupational codes by grouping together workers who perform similar tasks on the job. Over time, it modifies the codes, with most major revisions occurring during census years. To measure employment growth for a uniform set of occupations over a multi-decade period, I use Census occupational codes for 1990, as harmonized by Dorn (2009), Autor \& Dorn (2013), and Deming (2017). ${ }^{4}$ Each occupational code

\footnotetext{
${ }^{4}$ These codes were modified slightly to accommodate work in military-related occupations.
} 
has an attached set of jobs, which are defined in the Census Alphabetical List of Occupation Titles. I use these titles to create filters to capture AI-related job growth.

The creation of AI combines the efforts of workers with training across a wide range of technical disciplines, including computer engineering, computer science, data science, and software engineering. Supporting the workers who construct machine-learning algorithms and design their implementation on dedicated computer hardware are specialists who create and manage large databases, provide expertise in relevant domains (e.g., oncologists and radiologists for the use of AI to detect cancer), and develop and market AI products, among other tasks. In order to focus on jobs that are core to innovations in AI, I target the first group of occupations and not the second.

I define the universe of potential AI-related occupations as those in STEM, using the STEM definition in Hanson \& Slaughter (2018). They take the Census Bureau categorization of STEM jobs and remove those in which a relatively high fraction of workers lack a college degree (e.g., lab technicians, computer support staff, drafters). The resulting set of occupations includes all computer programmers, computer scientists, engineers, mathematical scientists, network systems analysts, and life and physical scientists. ${ }^{5}$

To define AI-related jobs, I apply a progressively finer set of filters to these broad STEM categories, which creates four versions of occupations:

- V.0 (version 0) occupations: I remove occupation codes from the Hanson \& Slaughter (2018) definition that appear to be related to administrative or supportive roles or that are tied to scientific disciplines that appear to be far removed from AI. ${ }^{6}$ The resulting set of modified STEM occupations had 707 titles in 2000, of which 137 were added between 1990 and 2000, as seen in Table 2.

- V.1 occupations: I select from V.0 occupations those whose titles have at least one of the following terms: analyst (subject to restrictions), architect, designer/design, developer, engineer, programmer, researcher/research, scientist, or statistician/statistical. The result set of potential AI occupations had 325 titles in 2000, of which 68 were added after 1990.

- V.2 occupations: I select from V.1 occupations those whose titles have at least one of

\footnotetext{
${ }^{5}$ To this list, I add financial and management analysts, which may include workers engaged in quantitative finance (an active area of AI). These categories are dropped in V.2, which contains broad AI titles.

${ }^{6}$ The excluded occupations, based on their 2000 Census codes, are: computer and information systems managers, engineering managers, financial specialists (all other), computer support specialists, database administrators, network and computer systems administrators, engineering technicians, computer operators, data entry keyers, and computer control programmers and operators. Among life and physical scientists, I exclude agricultural and food scientists, chemists and materials scientists, conservation and forestry scientists, and surveyors, cartographers, and mapping scientists.
} 
the following terms: designer/design, developer, programmer, researcher/research, scientist, and statistician/statistical; and engineer plus computer, data, or software. The resulting set had 146 titles across 18 occupation codes in 2000, of which 48 titles were added after 1990. This version is my broad definition of AI-related jobs.

- V.3 occupations: I select from V.2 occupations those that have at least one term from the group \{designer/design, researcher/research, scientist, or statistician/statistical\} and one term from the group \{computer, data, software\}. The resulting set has 30 titles across five occupation codes in 2000, of which 16 titles were added after 1990. This version is my narrow definition of AI jobs and is the baseline for the analysis. V.3 codes and titles appear in Appendix Table A.1.

Table 1 describes the application of the V.0 to V.3 filters to modified Census 1990 occupation codes and shows the total number of job titles as of 2000 for each version. In the empirical analysis, I use V.2 and V.3 occupations only. ${ }^{7}$

Appendix Table A.1 lists job titles for V.3 occupations. This narrow definition includes five Census 1990 occupations: computer hardware engineers, computer scientists and systems analysts, computer software engineers, network systems and data communications analysts, and statisticians. ${ }^{8}$ The 30 AI-related job titles include artificial intelligence specialist, information scientist, computer research, computer systems engineer, and software applications engineer. Whereas the first two of these are AI-specific jobs, the latter three are likely to span $\mathrm{AI}$ and non-AI-specific activities. Other job titles also appear likely to include AI and non-AI specific jobs (e.g., software requirements engineer, systems analyst engineer, computer engineer). By targeting job titles created after 1990, as I discuss in the next section, my approach helps narrow the focus on AI-related activities, but may do so imperfectly. The resulting measures of AI-related employment growth are therefore likely to include some non-AI jobs in information technology that nonetheless require AIlike skills. On the other hand, one may be concerned that designating just 30 job titles as being AI-related is too narrow. For this reason, I also use the broader V.2 definition of AI titles as a robustness check in the empirical analysis.

\footnotetext{
${ }^{7}$ In unreported results, I perform analysis for V.0 and V.1 occupations and obtain similar results.

${ }^{8}$ Note that the 30 job titles designated to be AI-related exclude many other titles within the five occupation codes that appear to be support roles, e.g., as indicated by the terms analyst, consultant, developer, integrator, planner, specialist, tester, or writer.
} 


\begin{tabular}{|c|c|c|c|c|}
\hline Version: & V.0 & V.1 & V.2 & V.3 \\
\hline \# identified titles: & 707 & 325 & 146 & 30 \\
\hline \multirow{25}{*}{ Occupation title filters } & Analyst & Analyst & & \\
\hline & Scientist & Scientist & Scientist & Scientist + Software/Data/Computer \\
\hline & Administration/administrator & & & \\
\hline & Researcher/research & Researcher/research & Researcher/research & Researcher/research + Software/Data/Computer \\
\hline & Designer/design & Designer/design & Designer/design & Designer/design + Software/Data/Computer \\
\hline & Architect & Architect & & \\
\hline & Technician & & & \\
\hline & Programmer & Programmer & Programmer & \\
\hline & Developer & Developer & Developer & \\
\hline & Integrator & & & \\
\hline & Engineer & Engineer & Engineer + Software/Data/Computer & Engineer + Software/Data/Computer \\
\hline & Statistician/statistical & Statistician/statistical & Statistician/statistical & \\
\hline & Manager & & & \\
\hline & Planning/planner & & & \\
\hline & Health & & & \\
\hline & Consultant & & & \\
\hline & Specialist & & & \\
\hline & Supervisor & & & \\
\hline & Tester & & & \\
\hline & Installer & & & \\
\hline & Coordinator & & & \\
\hline & Officer & & & \\
\hline & Operator & & & \\
\hline & Investigator & & & \\
\hline & etc. & & & \\
\hline
\end{tabular}

\section{Table 1: Occupation Title Filters for AI-Related Jobs}

This table reports keywords used to define versions V.0 to V.3 of occupational titles. These keywords act as inclusion criteria, subject to discretion. In particular, "analyst" is used in a wide variety of occupation titles, mandating many exclusions (e.g., "forms analysts"). V.0 applies no keyword filters; its associated column reports representative keywords that appeared in many of its occupation titles. The V.1 to V.3 filters are based on the listed keywords. They exclude engineering occupations that appear unconnected to AI (agricultural, biomedical, chemical, civil, environmental, industrial, marine, materials, mechanical, mining and geological, petroleum, and other engineers). 


\begin{tabular}{|c|c|c|c|c|c|c|c|c|c|}
\hline \multirow[b]{2}{*}{ Occupation } & \multirow[b]{2}{*}{ Total \# Occupation Titles } & \multicolumn{4}{|c|}{ \# AI Titles } & \multicolumn{4}{|c|}{ \# New, AI Titles } \\
\hline & & V.0 & V.1 & V.2 & V.3 & V.0 & V.1 & V.2 & V.3 \\
\hline Computer programmers & 22 & 22 & 18 & 18 & 0 & 11 & 10 & 10 & 0 \\
\hline Computer systems analysts and computer scientists & 162 & 97 & 52 & 34 & 24 & 65 & 32 & 24 & 15 \\
\hline Operations and systems researchers and analysts & 24 & 24 & 9 & 1 & 0 & 6 & 2 & 0 & 0 \\
\hline Engineers and other professionals, n.e.c. & 58 & 58 & 13 & 4 & 0 & 12 & 5 & 2 & 0 \\
\hline Atmospheric and space scientists & 19 & 19 & 17 & 17 & 0 & 3 & 3 & 3 & 0 \\
\hline Marine engineers and naval architects & 13 & 13 & 10 & 2 & 0 & 2 & 1 & 1 & 0 \\
\hline Electrical engineers & 60 & 60 & 54 & 9 & 3 & 9 & 5 & 3 & 1 \\
\hline Petroleum, mining, and geological engineers & 36 & 36 & 0 & 0 & 0 & 5 & 0 & 0 & 0 \\
\hline Mathematicians and statisticians & 27 & 27 & 13 & 10 & 3 & 3 & 0 & 0 & 0 \\
\hline Industrial engineers & 46 & 46 & 0 & 0 & 0 & 5 & 0 & 0 & 0 \\
\hline Mechanical engineers & 41 & 41 & 40 & 9 & 0 & 4 & 4 & 2 & 0 \\
\hline Chemical engineers & 23 & 23 & 16 & 2 & 0 & 2 & 2 & 1 & 0 \\
\hline Physicists and astronomers & 29 & 29 & 20 & 20 & 0 & 2 & 2 & 2 & 0 \\
\hline Biological scientists & 53 & 53 & 11 & 11 & 0 & 2 & 0 & 0 & 0 \\
\hline Civil engineers & 54 & 54 & 0 & 0 & 0 & 2 & 0 & 0 & 0 \\
\hline Management analysts & 31 & 31 & 7 & 0 & 0 & 1 & 0 & 0 & 0 \\
\hline Aerospace engineers & 42 & 42 & 37 & 9 & 0 & 1 & 0 & 0 & 0 \\
\hline Other financial specialists & 27 & 11 & 8 & 0 & 0 & 2 & 2 & 0 & 0 \\
\hline Metallurgical and materials engineers & 21 & 21 & 0 & 0 & 0 & 0 & 0 & 0 & 0 \\
\hline
\end{tabular}

Table 2: Occupation Codes and Numbers of Associated Titles

This table reports the following values for each occupation that contains job titles in the V.0 to V.3 definitions: the total number of occupation titles as of 2000 (column 2), the number of column 2 titles that are potentially related to AI (columns 3-6), and the number of column 3-6 titles that were new as of 2000 (columns 7-10). The final two metrics are shown for V.0 (STEM occupations), V.1 (potential AI occupations), V.2 (broad AI-related occupations), and V.3 (narrow AI-related occupations) categories. The remaining, unlisted 310 occupations had zero potentially AI-related titles. 


\subsection{AI-Related Employment Growth}

Although AI as a concept has been around for well over half a century, AI-specific occupations did not become prominent enough to merit their own job titles in public surveys until more recently. After slow progress in the 1970s and 1980s, advances in the field began to accelerate in the 1990s (Cockburn et al., 2018). ${ }^{9}$ I use the creation of new job titles after 1990 as an indication of the intensity of innovation across occupations.

The Census Bureau tracks how jobs change over time. To account for changes, it adds and subtracts job titles from occupational codes, where a title defines a specific job performed within an occupation. When the Census adds new titles to occupation codes, it indicates that there are new lines of work within an occupation that appear at sufficient frequency to merit official mention. Within my V.3 definition of AI-related jobs, after 1990 the Census added titles for artificial intelligence specialist and information scientist to the computer scientists and systems analysts occupational category (see Table A.1), which signified the expansion computer science jobs to include these fields. Lin (2011) uses the addition of new titles to measure the creation of new work at the level of an occupation code. Using his categorization, I define new AI-related work within an occupation using the job titles that were created after 1990 (by his designation) and that are AI-related (by my designation). ${ }^{10}$ I then measure employment growth in AI-related occupation codes, using the percentage increase in job titles that are AI-related as weights.

For occupation codes that register new titles in AI-related activities after 1990, Table 2 reports 1990 occupation categories in the first column, the total number of job titles for the occupation in 2000 in the second column, the number of titles for V.0 to V.3 occupations in 2000 in the next four columns, and the number of potentially AI-related titles added after 1990 for V.0 to V.3 occupations in the final four locums. After 1990, there were 48 new AIrelated job titles added in V.2 occupations, representing a 50.0\% $(=48 /(146-48))$ increase in job titles in the category, and 16 new AI-related job titles in V.3 occupations, representing a $114.3 \%(=16 /(30-16))$ increase in job titles in the category. For both definitions, the largest increase in job titles was for computer scientists and systems analysts.

\subsection{Alternative Approaches to Measuring AI}

To provide context for my analysis, I discuss other approaches to measuring AI-related production and work activities. Bloom et al. (2020) use earnings conference calls and

\footnotetext{
${ }^{9}$ Perhaps the signature AI achievement of the decade was IBM's Deep Blue machine-learning-based system defeating world champion Gary Kasparov in chess in 1997.

${ }^{10}$ Ideally, one would like to track the creation of new occupational titles separately for each decade. Such an exercise is unfortunately beyond the scope of this paper.
} 
patent filings to document the rollout of 20 new technologies between 2002 and 2000. For the 10 most-cited U.S. patents in each year between 1976 to 2016, they apply text analysis to identify the most common technical bigrams (e.g., word pairs) that appear in the filings for these patents. From the resulting bigrams, they identify those that appear most frequently in corporate earnings calls over 2002 to 2020 and then collect these terms into 20 technology groups. Of these 20, one is artificial intelligence (whose associated keywords are artificial intelligence, machine learning, neural networks, deep learning, predictive analytics, and language processing). Three other new technologies include applications of AI (driverless, machine vision, virtual reality), while two others are computing technologies that are used to create AI (cloud, disk drive).

Using this categorization, they calculate the exposure of firms and occupations to new technologies, where exposure to a specific technology is defined as the share of all technical bigrams that appear in earnings calls for a firm (from 2002 forward) or Burning Glass job postings for an occupation (from 2010 forward) that are comprised of the bigrams associated with that technology. These data allow Bloom et al. (2020) to track exposure to new technologies across U.S. industries, occupations, and regions. For AI, firm exposure increased modestly from 2010 to 2015 and rapidly thereafter. As a technology diffuses over time, the desired education level listed in job postings tends to decline.

For my purposes, their measure of technology exposure, which is not yet publicly available, represents a shock to labor demand that may be difficult to sign. For instance, the two most exposed occupations to virtual reality are computer hardware engineers and fine artists. One may imagine that the technology represents a strongly positive shock for engineers but an ambiguous shock for fine artists (e.g., positive for those working in digital media and negative for those working in non-digital media).

Other work focuses on identifying occupations exposed to the job-displacing impacts of AI. The measure in Felten et al. (2019) combines the Electronic Frontier Foundation AI Progress Measurement dataset, which tracks technological progress across categories of AI activities (e.g., image recognition), with crowdsourced assessments of how well these categories apply to $\mathrm{O}^{*} \mathrm{NET}$ ability scales (e.g., depth perception), to measure the vulnerability of occupations to AI, based on the importance of each ability scale to an occupation. In two related approaches, Brynjolfsson et al. (2019) use crowdsourcing to evaluate the suitability of machine learning for detailed work activities in $\mathrm{O}^{*} \mathrm{NET}$, and then construct an occupation-level measure of exposure to AI based on occupation intensities in these activities, while Webb (2020) defines occupation-level exposure by identifying the overlap between Google Patents Public Data and O*NET tasks. Acemoglu et al. (2020) calculate exposure to AI at the establishment level by using the establishment intensity of employ- 
ment across occupations for each of these three AI occupation-exposure measures.

These advances in measuring occupation or establishment-level exposure to the disruptive impacts of AI are welcome. None, however, appears to be directly useful for detecting which occupations are most likely to be engaged in producing AI.

\section{Preliminary Analysis}

In this section, I examine which U.S. commuting zones are most specialized in AI-related activities, in which commuting zones are AI-related activities most concentrated, and how revealed comparative advantage in AI-related activities various across workers according to their region of birth. I focus on prime-age workers (ages 25 to 54) who have at least four years of college education. I measure employment as hours worked (weeks worked last year $\times$ usual hours worked per week $\times$ sampling weight) for individuals not in group quarters who had positive earnings in the previous year. Data are from the 2000 Census, the 2005-2009 ACS five-year sample (which I ascribe to 2009), and the 2014-2018 ACS five-year sample (which I ascribe to 2018).

\subsection{CZ Specialization in AI-Related Occupations}

Figure 1 shows the share of hours worked by the college-educated in AI-related occupations for the V.3 definition across commuting zones. Unreported figures for the V.2 definition of occupations are very similar. The first panel shows the share of all CZ workers employed in AI-related occupations, first for men and then for women; the second panel shows foreign-born workers employed in AI-related occupations as a share of total CZ employment; and the third panel shows native-born workers employed in AI-related occupations as a share of total $\mathrm{CZ}$ employment. ${ }^{11}$ In each graph, the share of $\mathrm{CZ}$ employment in AI-related jobs for 2018 appears on the vertical axis and the corresponding share for 2000 appears on the horizontal axis. To help identify the individual CZs in the figures, Appendix Table A.2 lists the top $20 \mathrm{CZs}$ in each of the six plots. Unreported plots for employment shares using worker counts are very similar.

Three patterns are apparent in the data. The first is that there is persistence in which CZs are specialized in AI-related activities. In each figure, there is a strong positive correlation between the share of CZ employment in AI-related jobs in 2000 and 2018, as indicated by the clustering of points along the 45-degree line. Most points are modestly

\footnotetext{
${ }^{11}$ The shares in the second and third panels add to the total shares shown in the first panel.
} 
to substantially above the line, indicating a strengthening of regional specialization in AIrelated activities over time. The second is that across CZs and over time specialization of men in AI-related activities tends to be much stronger than that for women. Male AI employment shares tend to be two to three times as large as those for women. This pattern is consistent with the relatively greater specialization of men in STEM-related jobs across occupations (e.g., Hanson \& Slaughter, 2018).

The third pattern relates to differences in native-born and foreign-born specialization in AI-related activities across CZs. When considering all workers together in the first panel, specialization in AI-related activities is strongest in three types of CZs: hubs for high-tech industry (e.g., San Jose, CA), university towns (e.g., Bloomington, IL), and cities specialized in government or military research (e.g., Colorado Springs, CO). When I separate foreign-born and native-born workers, we then see that when it comes to specialization in AI-related activities the two groups of workers tend to cluster in different places. The share of foreign-born workers specialized in AI-related activities as a share of $\mathrm{CZ}$ total employment is largest in conventional high-tech hubs (San Jose, CA; Oakland, CA; Austin, TX; Boston, MA; Seattle, WA), and a few major cities (New York, NY; Washington, NY; Dallas, TX). For the native-born, by contrast, the share of their employment in AI-related activities as a share of $\mathrm{CZ}$ total employment is highest in locations that have government, military, or space-related research facilities (Colorado Springs, CO; Alexandria, VA; Melbourne, FL; Huntsville, AL) or that are university towns (Bloomington, IL; Provo, UT). For both men and women, the overlap of the top $10 \mathrm{CZs}$ in terms of AI specialization by the foreign-born and native-born includes just two commuting zones, Washington, DC, and Raleigh, NC. Because government and military research tends to require higher-level security clearances, it may be that native-born workers are better positioned to take these types of jobs. Foreign-born workers appear to excel in taking up jobs in CZs populated by private employers and non-governmental research entities. 
Figure 1: Share of Hours Worked in AI-Related Occupations by Commuting Zone
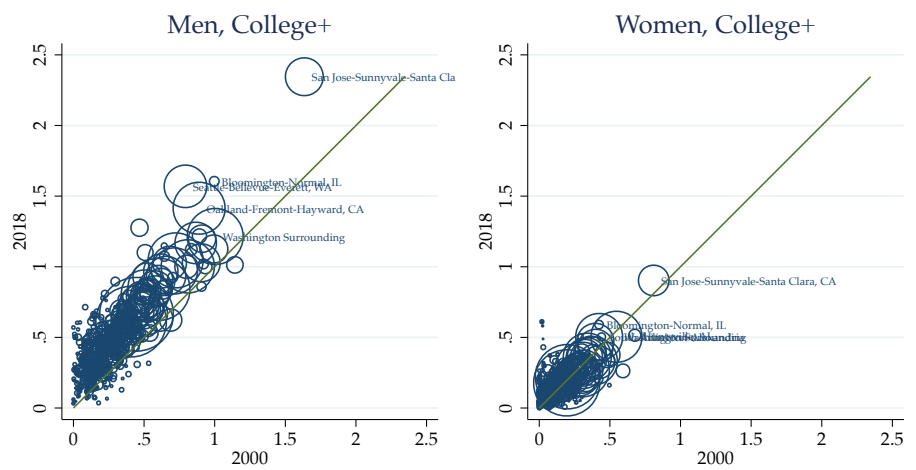

(a) All Workers
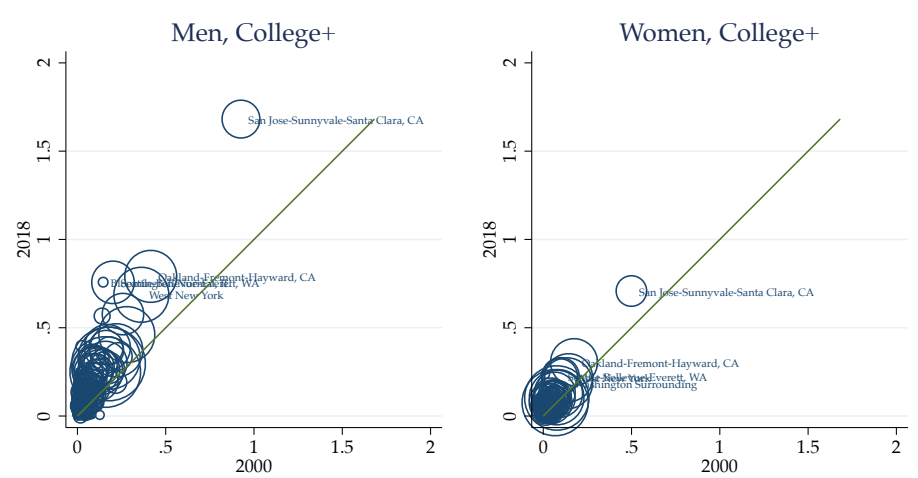

(b) Foreign-born Workers
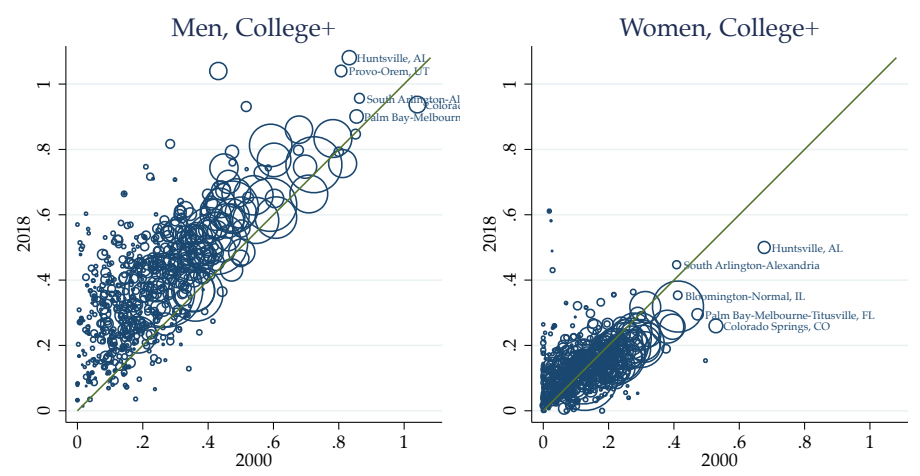

(c) Native-born Workers

The figures show the share of hours worked (in percentage terms) in AI-related occupations (V.3 definition) for prime-age, college-educated men or women in a given CZ for 2000 and 2018. AI hours worked is measured as hours worked in a given AI-related occupation times the share of all 2000 jobs titles in that occupation that were created after 1990 and that were AI-related. Shares are for all workers in panel (a), foreign-born workers in panel (b), and native-born workers in panel (c). 


\subsection{Concentration of AI-Related Employment in Tech-Oriented CZs}

Figure 2 shows the share of commuting zones in national hours worked by the collegeeducated in AI-related occupations by the V.3 definition, where figures for the V.2 definition are very similar. The first panel includes all workers, first for men and then for women; the second panel includes foreign-born workers only; and the third panel includes native-born workers only. In each graph, the $\mathrm{CZ}$ share of national employment in AI-related jobs for 2018 appears on the vertical axis and the corresponding share for 2000 appears on the horizontal axis. To help identify the individual CZs in the figures, Appendix Table A.3 shows the top $20 \mathrm{CZs}$ in each of the six figures. Unreported plots for employment shares using worker counts are very similar.

The largest hubs account for a substantial share of US AI-related employment. These patterns are persistent over time, as indicated by the concentration of data points along the 45-degree line. The top five hubs (Washington, Los Angeles, Oakland, Chicago, San Jose) accounted for $23.1 \%$ of male AI-related employment in 2018 and the top 10 (top five plus Boston, New York, West New York, Atlanta, Dallas) accounted 40.9\% of male AIrelated employment in that year. Figures for women are similar, as are the CZs in which their employment is concentrated. Consistent with overall patterns of spatial agglomeration in high-tech activities (Moretti, 2012, 2019; Bloom et al., 2020), US employment in jobs that require AI-like skills are highly geographically concentrated.

As with regional specialization in AI-related jobs, it is again the case that the commuting zones that account for the the largest clusters of AI-related employment differ depending on whether one is examining foreign-born or native-born workers. For foreign-born men, San Jose (8.6\% in 2018) and Oakland (8.1\% in 2018) are the largest clusters of AIrelated employment, whereas for native-born men San Jose (1.8\% in 2018) and Oakland (3.4\% in 2018) are numbers 12 and five, respectively. For native-born men, Washington, DC (4.9\% in 2018) and Boston (3.3\% in 2018) are the largest clusters of AI-related employment, whereas for foreign-born men Washington, DC (5.6\% in 2018) and Boston (3.7\% in 2018) are numbers five and eight, respectively. This provides further evidences of differences in specialization patterns of the foreign and native-born when it comes to AI-related jobs. We turn next to examine these specialization patterns in more detail. 


\section{Figure 2: Share of CZ in National Hours Worked in AI-Related Occupations}
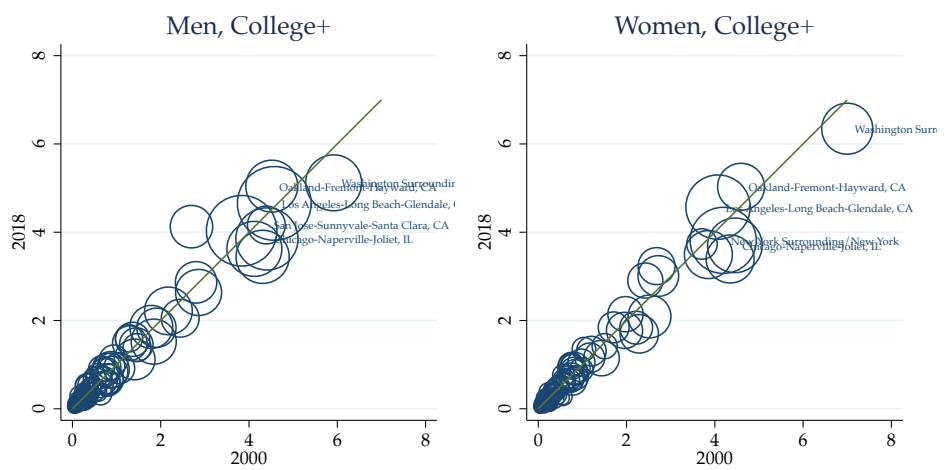

(a) All Workers
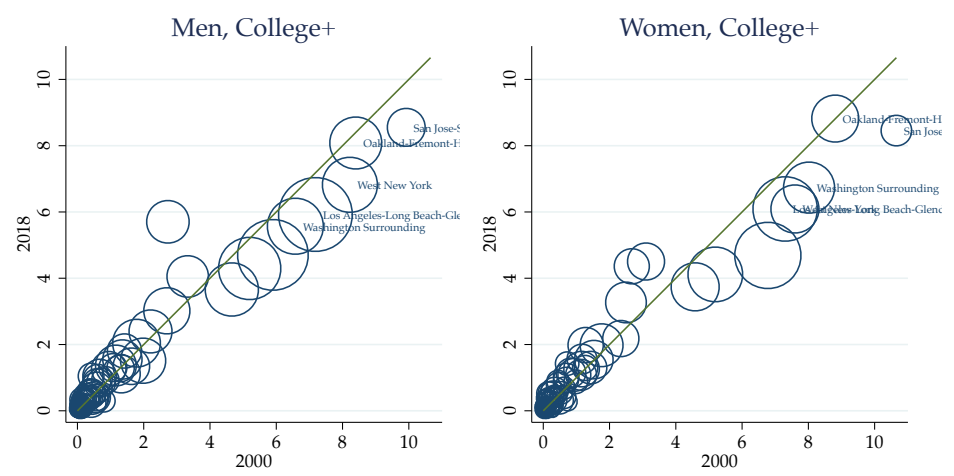

(b) Foreign-born Workers
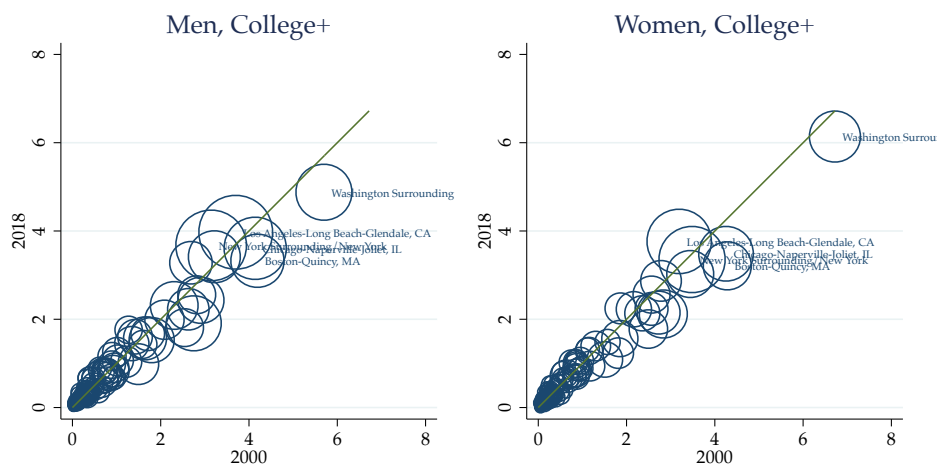

(c) Native-born Workers

The figures show the share of a commuting zone in national hours worked (in percentage terms) in AIrelated occupations (V.3 definition) for prime-age, college-educated men or women in a given CZ for 2000 and 2018. AI hours worked is measured as hours worked in a given AI-related occupation times the share of all 2000 jobs titles in that occupation that were created after 1990 and that were AI-related. Shares are for all workers in panel (a), foreign-born workers in panel (b), and native-born workers in panel (c). 


\subsection{Revealed Comparative Advantage in AI-Related Occupations}

In this section, we consider the extent to which foreign and native-born workers differ in their specialization in AI-related jobs. Existing literature indicates that across all STEMrelated occupations, the foreign-born show stronger patterns of specialization than do the native-born (Hanson \& Liu, 2017; Hanson \& Slaughter, 2018). Here, we narrow the focus to the revealed comparative advantage of the two groups in jobs that are related to AI.

To begin, Figure 3 shows the share of hours worked by the prime-age and collegeeducated in AI-related occupations (V.3 definition) by worker place of birth. I group birth countries into eight regions based on similarities in education levels and specialization in STEM occupations: the US; Africa and the Middle East; China and Hong Kong; Europe, Australia and New Zealand; India; Korea, Japan, and Taiwan; Latin America and the Caribbean; and Other Asia. ${ }^{12}$ For men, the share of AI-related jobs (V.3 definition) held by those born in the US declined from $75.2 \%$ in 2000 to $65.2 \%$ in 2018. This drop was due almost entirely to the increased employment of men born in India, whose share of AIrelated employment rose from $7.8 \%$ in 2000 to $16.9 \%$ in 2018. Over 2000 to 2018, foreignborn workers accounted for $54.6 \%$ of the increase in employment in AI-related jobs, with workers born India alone accounting for $63.7 \%$ (or $35.3 \%$ of the nationwide increase) of this increase. Patterns for women are similar. The share of native-born women in AIrelated employment fell between 2000 and 2018 (from $78.1 \%$ to $65.1 \%$ ), with rising shares for women born in India (from $4.8 \%$ to $16.4 \%$ ) accounting for most of this decline.

To characterize specialization in AI-related jobs, one needs to adjust for the overall presence of workers from different national origin groups in the economy. I do so by calculating revealed comparative advantage in AI-related employment, defined as,

$$
R C A_{n}=\ln \left(\frac{L_{n}^{a i} / L^{a i}}{L_{n} / L}\right),
$$

where $L_{n}^{a i} / L^{a i}$ is the share of national-origin group $n$ in US employment (of the college educated) in AI-related occupations (which is shown in Figure 3 ) and $L_{n} / L$ is the share of national-origin group $n$ in national employment (of the college educated) across all occupations. RCA values for men and women in 2000 and 2018 appear in Figure 4. Workers born in India display the strongest revealed comparative advantage in AI-related employment. The log RCA value for Indian men of 1.37 in 2018 indicates that their employment share in AI was $3.9(=\exp (1.37))$ times their employment share across all occupations in the US. Women born in India display an even stronger revealed comparative advantage

\footnotetext{
${ }^{12}$ See Appendix Tables A.6 and A.8 for the values reported in these figures as well as values for the V.2 definition of AI-related jobs.
} 
in AI-related activities. For both men and women, China and Hong Kong is the region with the next strongest RCA in AI-related jobs. Robustly negative log RCA values for individuals born in the US and Latin America and the Caribbean indicate that among the college educated their employment shares in AI-related activities were substantially below their employment shares across all occupations.

It its natural to wonder whether the revealed comparative advantage we observe on the part of Indian and Chinese workers in AI-related occupations simply reflects a generic comparative advantage across all jobs that are related to STEM disciplines. To investigate this possibility, Appendix Tables A.4 to A.8 show employment shares and log RCA values for national origin groups using the V.0 definition of STEM-related jobs (707 titles), the V.1 definition of potentially AI-related jobs (325 titles), and the V.2 broad definition of AI-related jobs (146 job titles). These categories represent substantially larger employment levels than the 30 AI-related job titles in the V.3 definition. In 2018, workers born in India accounted for $4.3 \%$ of total employment of college-educated men in the US, $10.9 \%$ of employment in V.0 occupations, $12.1 \%$ of employment in V.1 occupations, and $14.6 \%$ of employment in V.2 occupations, as compared to their $16.9 \%$ of employment in V.3 occupations. A similar patterns holds for women born in India, whose employment shares rise from $2.2 \%$ among all college-educated workers to $9.3 \%$ in V.0 occupations and to $16.4 \%$ in V.3 occupations. As we narrow the definition of jobs related to AI, the revealed comparative advantage of workers from India in these occupations intensifies. For men born in China or Hong Kong, their 2018 employment shares rise from 1.4\% across all occupations to $2.7 \%$ in V.0 occupations and to $3.4 \%$ in V.3 occupations, while for women born in the region their employment shares rise from from $1.4 \%$ across all occupations to $4.3 \%$ for V.0 occupations and to $5.3 \%$ for V.3 occupations. For workers born in India and China, specialization in narrowly defined AI-related jobs is much stronger than specialization in STEM-related occupations overall.

Which factors account for the revealed comparative advantage of workers from China and India in AI-related activities? One may be the quality of technical training in engineering and math in the two countries. China has invested heavily in its university training in STEM (Xie \& Freeman, 2020), while India's technical institutes excel in engineering and math. Strong engineering and math skills may have left workers from the countries well-positioned to move into AI as the field has expanded.

A related factor, which may be both a result of and a contributor to the countries' revealed occupational comparative advantage in computer science and engineering, is the exceptional capabilities of Indian and Chinese firms in technology fields. Indian firms, such as Infosys, Tata Consultancy Services, and Wipro, are among the leading providers 
of technology-related services globally. These companies do not compete head to head with Alphabet, Amazon, Apple, Facebook, Microsoft, or other major US tech companies. Instead, they provide programming and other technical services to them. Indian tech firms may offer a training ground for workers who wish to obtain visas to work in the US. For its part, China has developed a set of national technology companies in Alibaba, Baidu, and Tencent that occupy similar market niches as the big five US tech firms. Because of barriers to entry in China, the two groups of companies tend not to compete head to head in their national markets. Like Indian companies, these firms may provide a training ground for workers seeking to break into the US job market.

A third factor may be US immigration policy. Prior to 1990, there were few individuals of Indian or Chinese origin (either in absolute terms or relative to their national populations) in the US. As a result, few US residents would have been able to sponsor individuals from these countries for family-based immigration visas, which by law account for the strong majority of permanent visas that the US government gives out each year. Their primary means of obtaining a US permanent legal residence visa, or green card, has been through employer-sponsored visas, the supply of which equal a legally mandated $15 \%$ of all restricted visas (i.e., visas other than those awarded to immediate family members of US residents) awarded in a given year. The need to obtain employer-sponsored green cards may have meant that the Indian and Chinese immigrants selected for admission have been disproportionately likely to reflect the types of high-skilled workers in most demand by US companies, including those in high tech.

H-1B visas, which were introduced in 1990 and allow workers to hold a job in the US for three years and to renew the visa for a second three-year stay, are claimed overwhelmingly by workers in technology-related fields (Bound et al., 2017, 2021). These visas operate effectively as queues for employer-sponsored green cards. One pathway to an employer sponsored green card is first to obtain an H-1B temporary work visa, which allows a worker to demonstrate her talents to a US employer before that employer undertakes the time-consuming task of employment sponsorship. A second and related pathway is first to obtain a student visa, then to complete an undergraduate or graduate degree in the US, and finally to secure an $\mathrm{H}-1 \mathrm{~B}$ visa. The need for many Chinese and Indian immigrants to obtain an $\mathrm{H}-1 \mathrm{~B}$ visa to gain entry to the US may create a selection mechanism that favors workers who excel in jobs that require skills applicable to AI. 
2000
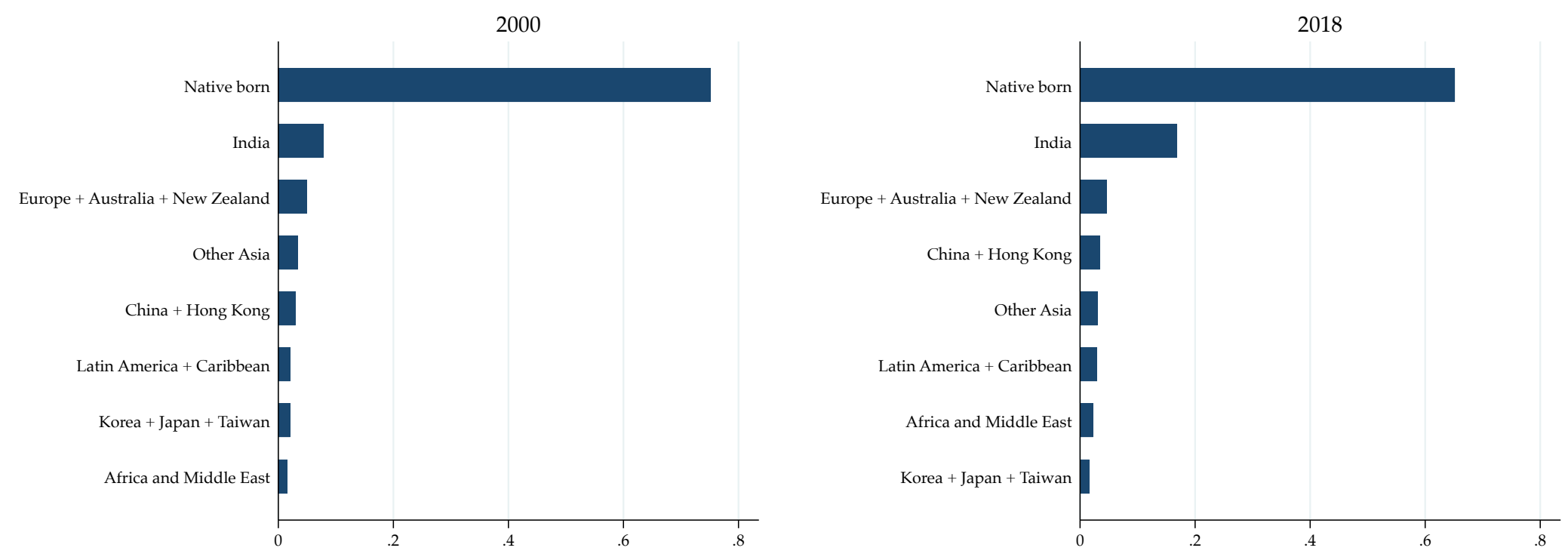

(a) Men

2000

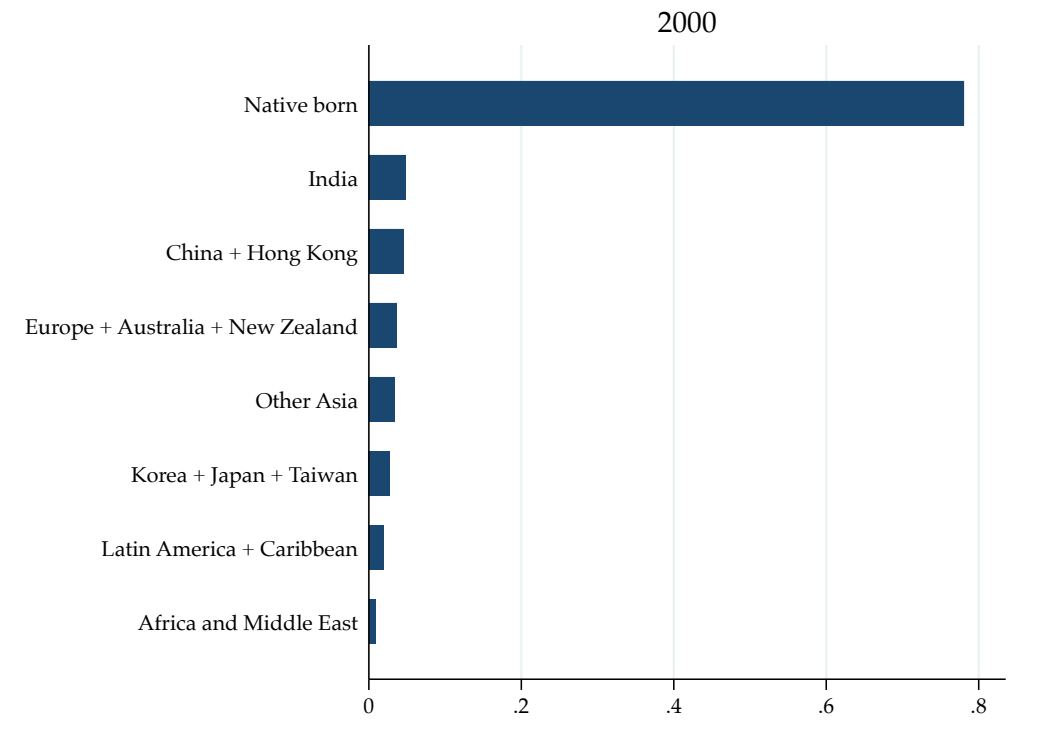

(b) Women

Figure 3: Share of Hours Worked by the College Educated in AI-Related Occupations by Worker Region of Birth 

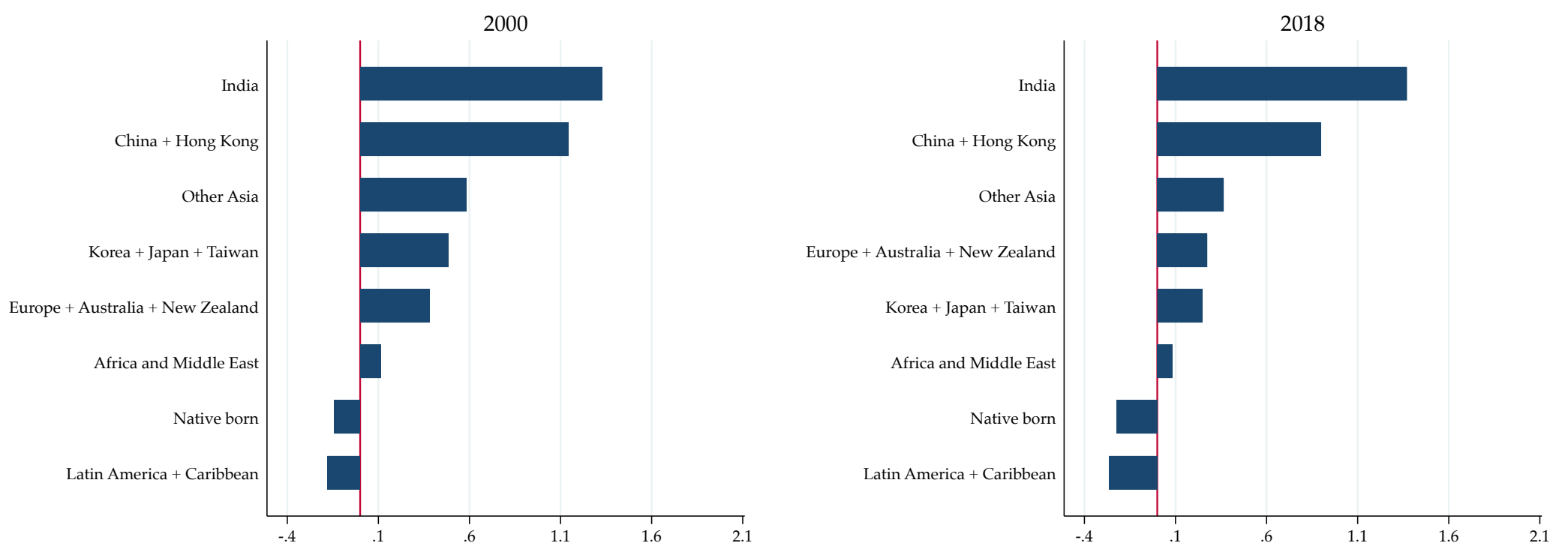

(a) Men
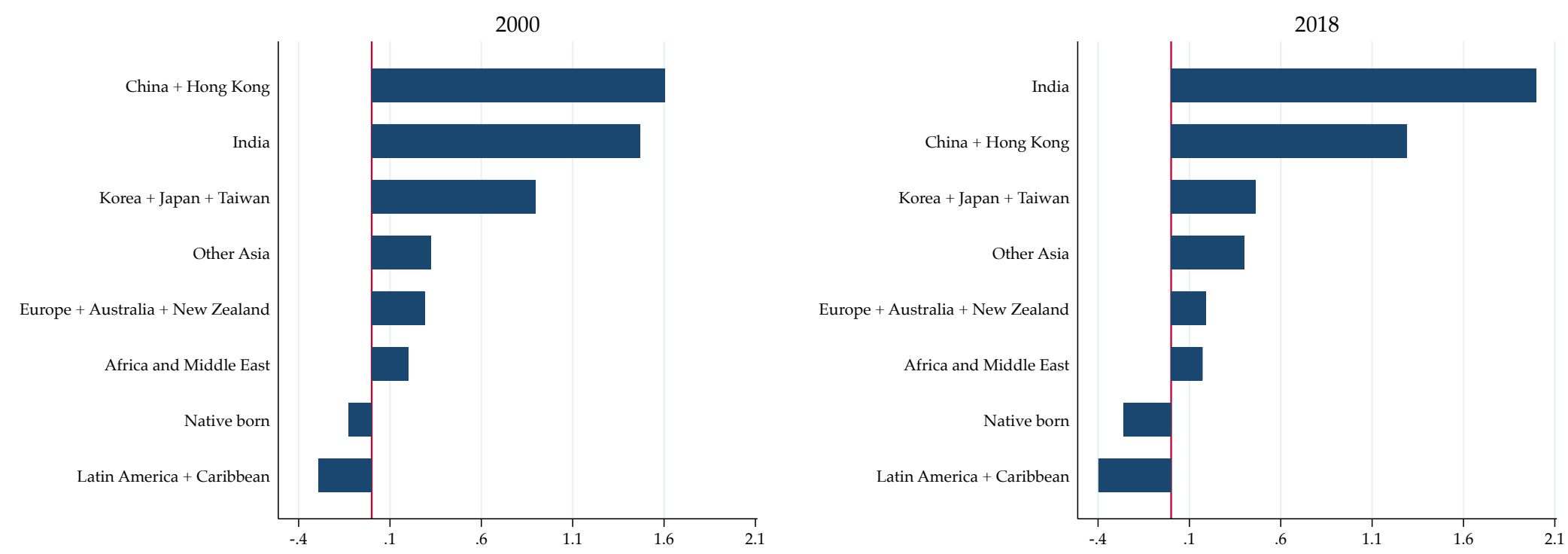

(b) Women

Figure 4: Revealed Comparative Advantage in AI-Related Occupations for College-Educated Workers by Region of Birth 


\section{Regression analysis}

In this section, I present the core empirical results of the paper. I estimate the change in CZ specialization in AI-related activities as a function of the immigrant labor-supply shock confronting the $\mathrm{CZ}$, defined as local exposure to national growth in the number of college-educated immigrants. The estimation covers the long-period change 2000 to 2018; results for stacked first differences over 2000 to 2009 and 2009 to 2018 are shown in the appendix. This time period spans the slower growth in AI-related activities of the early 2000s and the acceleration in growth after 2010. All specifications control for regional business cycles and initial-period $\mathrm{CZ}$ demographic composition and exposure technological change, manufacturing decline, and globalization.

\subsection{Empirical Specification}

The core empirical specification takes the form,

$$
\triangle Y_{c g \tau}^{v}=\beta_{g 0}+\beta_{g 1} \triangle z_{c g \tau}^{v}+\beta X_{c g \tau}+\epsilon_{c g \tau},
$$

where $\Delta Y_{c g \tau}^{v}$ is the change in the share of employment for prime-age, college-educated workers of gender $g$ (female, male) in commuting zone $c$ (722 CZs in the continental US) in AI-related occupations of type $v$ (V.3, V.2) over time period $\tau$ (2000-2018). ${ }^{13}$ I use hours worked to measure employment in the baseline analysis; results using worker counts appear in the appendix. I estimate equation (1) separately for men and women. I measure the employment change in the numerator of the dependent variable to be, alternatively, for all workers, foreign-born workers, and native-born workers (such that the estimated $\beta_{g 1}$ values for the latter two groups sum to that of the first group).

The immigrant labor-supply shock, $\triangle z_{c \tau}^{v}$, is defined as follows (where all values are gender-group specific and from here forward I suppress the gender-group index):

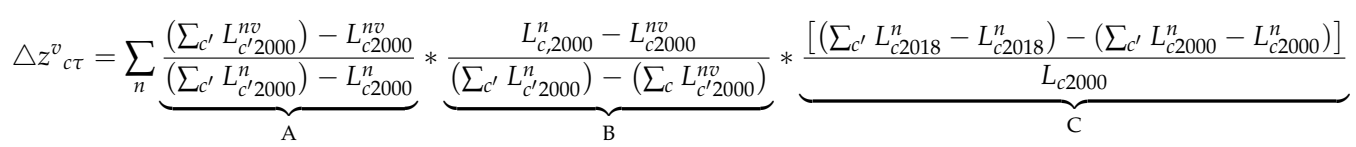

This shock, which follows the logic of shift-share instruments for immigrant labor supply developed by Altonji \& Card (1991) and Card (2001), is the function of three terms. Term $C$ is the change in the employment of prime-age, college-educated individuals of a given

\footnotetext{
${ }^{13}$ Both the dependent variable, $\triangle Y_{c g \tau}^{v}$, and the immigration labor-supply shock, $\triangle z_{c g \tau}^{v}$, are expressed in decadalized terms by multiplying them by $10 / \triangle t$, where $\Delta t$ is the length of time period $\tau$.
} 
gender for national-origin group $n$ outside of $\mathrm{CZ} c$ over period $\tau$ (e.g., the change in the number of college-educated Indians in the US living outside of Austin between 2000 and 2018), normalized by the employment of prime-age, college-educated individuals in CZ $c$ in the initial period. By leaving out quantities of $\mathrm{CZ} c$ in the numerator of this term, I utilize information on immigration of group $n$, excluding those migrants who chose $\mathrm{CZ} c$ as their destination (and may have been motivated by economic conditions in $c$ in making their emigration decision). This value therefore summarizes the generic attraction of college-educated immigrants of national origin group $n$ to the US over time period $\tau$.

Term $B$ is the share of workers from national-origin group $n$ employed outside of AI-occupation-group $v$ that resided in $\mathrm{CZ} c$ in the year 2000. Excluding AI-related occupations in this share captures the initial-period attraction of $\mathrm{CZ} c$ to college-educated immigrants from origin $n$ that is generic to the $\mathrm{CZ}$ and not specific to AI-related activities. Term $A$ is the share of college-educated workers of national origin group $n$ outside of $C Z$ $c$ that worked in AI occupation group $v$ in the initial time period. Excluding $\mathrm{CZ} c$ from this value captures the generic specialization of national origin group $n$ in AI-related activities. Multiplying terms $A, B$, and $C$, and then summing across national origin groups produces the imputed inflow of immigrant workers in AI-related occupations to a CZ, which is based on the specialization of immigrants in AI-related occupations (outside of the $\mathrm{CZ}$ ), the concentration of different immigrant groups in the $\mathrm{CZ}$ (outside of AI-related activities), and national growth in immigrant populations (outside of the $\mathrm{CZ}$ ). The specification in (1) is therefore equivalent to a first-stage regression in which the CZ employment of workers in AI-related occupations is the endogenous variable and the projected change in $\mathrm{CZ}$ immigrant labor supply is the instrument.

The vector of control variables $X_{c g \tau}$ includes state fixed effects (to control for regional business cycles); the sum of the shares in (2) (i.e., $\sum_{n} A_{c n} B_{c n}$ which follows the recommendation of Borusyak et al. (2018) when using shift-share shocks as regressors); and CZ shares for the year 2000 of the college educated in the population, the foreign-born in the population, women in total employment, employment in manufacturing (to control for secular trends in the sector), employment in routine-intensive jobs (to control for exposure to automation and related forms of skill-biased technological change), and employment in offshorable jobs (to control for exposure to globalization). The third group of controls follows those used by Autor et al. (2013) in their analysis of local-labor-market adjustment to trade-related, labor-demand shocks. I cluster standard errors by state and weight regressions by $\mathrm{CZ}$ total employment (of prime-age, college educated workers of the given gender group) in the initial period. Summary statistics for the dependent variables and immigration-shock measures used in the analysis appear in Appendix Table A.9. 


\subsection{Baseline Estimation Results}

The baseline estimation results appear in Table 3, where AI-related occupations are defined for the narrow V.3 job titles. All coefficients except those for the immigration shock are suppressed. Consider first the results for all men, shown in column 3 of the first panel. The coefficient estimate of 1.68 ( $\mathrm{t}$-value $=2.56$ ) implies that when comparing CZs at the $75^{\text {th }}$ and $25^{\text {th }}$ percentiles of exposure to the immigrant labor-supply shock, the more exposed CZ would have a $0.08(=1.68 \times(0.08-0.03))$ larger annual percentage-point increase in the share of college-educated men employed in AI-related activities. This increase represents a full standard-deviation change in the dependent variable.

Columns 1 and 2 decompose the dependent variable in column 3 into two terms: the portion due to the increase in the employment of the foreign-born and the portion due to the increase in the employment of the native-born. By construction, coefficients in columns 1 and 2 sum to that in column 3. The highly precise coefficient estimate of 1.93 $(\mathrm{t}$-value $=4.69)$ in column 1 implies that when comparing CZs at the $75^{\text {th }}$ and $25^{\text {th }}$ percentiles of exposure to the immigrant labor-supply shock, the more exposed CZ would have a $0.09(=1.93 \times(0.08-0.03))$ larger annual percentage-point increase in the share of college-educated men who are employed in AI-related activities and who are foreign born, which represents a 1.2 standard-deviation increase in the dependent variable. By contrast, in column 2 when the dependent variable is the change in native-born men employed in AI the coefficient on the immigration shock is small, negative, and imprecisely estimated $(\beta=-0.24$, $\mathrm{t}$-value $=0.75)$. This means that the immigrant labor-suppy shock works to expand employment in AI-related activities entirely through increased employment of the foreign born. The shock neither crowds in nor crowds out the employment of native-born men in AI-related occupations.

The concentrated impact of immigrant labor-supply growth on foreign-born AI employment is notable because nationally foreign and native-born workers have contributed roughly equally to the increase in AI employment. Of the mean change in the share of men employed in AI over 2000 to 2018 in Table A.9, 54.6\% is due to greater employment of the foreign-born and $45.4 \%$ is due to greater employment of the native-born. Despite this similar contribution, the two groups have responded quite differently to localized high-skilled immigrant labor-supply shocks. Consistent with the descriptive evidence in Figures 1, the factors driving expanded AI-related regional employment for the foreignborn appear to be distinct from those for the native-born. 
Table 3:

Long difference (2000-2018): Immigration Impact on CZ Specialization in AI-Related Occupations (V.3)

\begin{tabular}{|c|c|c|c|c|c|c|}
\hline & \multicolumn{3}{|c|}{ Men } & \multicolumn{3}{|c|}{ Women } \\
\hline & Foreign-born & Native-born & All & Foreign-born & Native-born & All \\
\hline & $(1)$ & $(2)$ & (3) & (4) & (5) & (6) \\
\hline Immigrant shock (v3) & $\begin{array}{c}1.927 \\
(0.411)\end{array}$ & $\begin{array}{c}-0.242 \\
(0.324)\end{array}$ & $\begin{array}{c}1.684 \\
(0.658)\end{array}$ & $\begin{array}{c}0.776 \\
(0.393)\end{array}$ & $\begin{array}{c}0.107 \\
(0.262)\end{array}$ & $\begin{array}{c}0.883 \\
(0.626)\end{array}$ \\
\hline State FE & Yes & Yes & Yes & Yes & Yes & Yes \\
\hline Obs. & 722 & 722 & 722 & 717 & 717 & 717 \\
\hline Adj. R-squared & 0.797 & 0.380 & 0.541 & 0.695 & 0.528 & 0.304 \\
\hline DV Mean & 0.076 & 0.063 & 0.139 & 0.019 & -0.018 & 0.001 \\
\hline DV 25th percentile & 0.032 & 0.026 & 0.107 & 0.005 & -0.040 & -0.020 \\
\hline DV 75th percentile & 0.088 & 0.090 & 0.167 & 0.027 & -0.002 & 0.017 \\
\hline
\end{tabular}

The dependent variable is the change in the share of hours worked in AI-related occupations (V.3 definition) for the long difference 2000-2018 for men (columns 1-3) and women (4-6), shown separately for all workers (columns 5 and 6), foreign-born workers (columns 1 and 2), and native-born workers (columns 3 and 4). The immigrant shock for AI-related occupations (V.3 definition) is defined in equation (2). The sample is individuals 25 to 54 years old with at least a bachelor's degree residing in one of the 722 commuting zones in the continental US. All regressions include a constant, the summed product of the weights used in the immigration shock, state fixed effects, and initial-period shares of the college educated in the population, the foreign-born in the population, females in total employment, employment in manufacturing, employment in routine-intensive jobs, and employment in offshorable jobs. Standard errors (in parentheses) are clustered by state. Regressions are weighted by CZ employment (of prime-age, college educated workers of the designated gender) in the initial period. 
It is important to note that the results in Table 3 are not mechanical. CZs exposed to a larger overall increase in college-educated immigration experience larger employment growth specific to AI-related activities. Because AI-related occupations account for a very small share of total employment, there is no automatic connection between the expanded supply of college graduates in a CZ and greater specialization in AI-related activities. The results for women, to which I now turn, confirm this reasoning.

Estimation results for women appear in the second panel of Table 3. Impacts of the immigration supply shock on AI-related employment of all college-educated women, shown in column 6 , are positive but imprecisely estimated $(\beta=0.88$, $\mathrm{t}$-value $=1.41)$. This overall effect combines a positive but small and imprecise impact on the AI employment of native-born women in column $5(\beta=0.11$, $\mathrm{t}$-value $=0.42)$ and a larger, positive, and more precisely estimated impact on the AI employment of foreign-born women in column $4(\beta=0.78$, $\mathrm{t}$-value $=1.98)$. Given the differential specialization of men and women in AI-related jobs-over 2000 to 2018, employment shares in AI-related occupations rose by 0.14 percentage points annually for men but just 0.001 percentage points annually for women - the immigration labor-supply shock has substantially larger impacts on male versus female employment. By the same token, the specialization of foreign-born men in AI-related activities means that increased access to college-educated male immigrants drives a region to specialize more strongly in AI-related activities.

Burstein et al. (2020) provide a theoretical framework that explains how exogenous increases in the supply of foreign-born workers to specific occupations need neither crowd in nor crowd out the employment of native-born workers, at least in jobs whose output is tradable. Tradability implies that firms can absorb immigrant workers in an occupation (e.g., using machine learning to create AI) by expanding exports to other regions. As long as a region is small in the sense of its output changes having minimal impacts on prices in national or global markets, then the expansion in the employment of the foreign born need not displace any native-born workers, even where foreign and native-born workers are perfectly substitutable on the job. Because AI-related occupations are highly tradable, the results in Table 3 appear to be consistent with Burstein et al. (2020) logic.

Beyond the tradable-sector adjustment mechanism, there may be other factors at work that affect how foreign and native-born workers sort themselves across jobs related to AI. AI has many applications in national defense, national intelligence, and space-related research (Allen \& Chan, 2017). Jobs in these applications, whether they be for private employers, universities, non-profit research organizations, or the government, often require a security clearance. Native-born workers may be better positioned to acquire such clearances. Although Census and ACS data do identify whether or not workers are em- 
ployed by government entities, the data are not sufficiently granular to identify which private employers are engaged in activities related to national security. One task for future research is to evaluate whether greater access to high-skilled immigrant labor leads a region to adjust the types of AI activities in which it engages.

\subsection{Robustness Checks}

Next, I explore the robustness of the empirical results in three dimensions. First, I use alternative measures of employment. Appendix Table A.10 displays results using worker counts, rather than hours worked, to measure employment. For men and women and all nativity groups, the results in Table A.10 are very similar to those in Table 3. The implication is that the immigration shock has comparable impacts on the intensive margin (hours worked) and extensive margin (worker counts) of AI employment.

Second, I adjust the definition of time periods used in the analysis. Instead of the 2000 to 2018 long difference, I organize the data in stacked first differences over two time periods, 2000 to 2009, during which growth in AI was relatively slow, and 2009 to 2018, during which growth in AI was relatively rapid (Bloom et al., 2020). The results, which appear in Appendix Table A.12, are very similar in terms of coefficient signs and magnitudes to those in Table 3. Shortening the time periods and expanding the sample size allows for more precision in the coefficient estimation. For women, the impact of the immigration shock on employment in AI-related occupations is now positively and strongly precisely estimated for all women and for foreign-born women. The impact on native-born women remains small and imprecisely estimated.

Finally, I broaden the definition of AI-related occupations. The V.3 measure I have used so far in the estimation defines AI jobs to comprise 30 job titles, of which 16 were created after 1990. The broader V.2 definition includes 146 job titles, of which 48 were created after 1990. Table 4 reports results for V.2 AI-related occupations using employment measured as hours worked, and the 2000 to 2018 long difference. Appendix Tables A.11 and A.13 show corresponding V.2 results for employment measured using worker counts and stacked first differences over 2000 to 2009 and 2009 to 2018, respectively. For men, the results in Tables 3 and 4 are qualitatively similar. For either measure, the high-skilled immigration shock has a strongly positive impact on employment in AI-related occupations, which is due entirely to the expanded employment of the foreign born. The results differ in terms of magnitudes. The coefficient on the immigration shock for V.3 occupations is twice as large $(1.95=1.93 / 0.99)$ as for V.2 occupations. For women, the change in coefficient magnitudes is even more substantial. The immigration shock coefficient for 
foreign-born women in Table 4 is only one-third $(0.36=0.78 / 0.28)$ as large as in Table 3 and is quite imprecisely estimated ( $\mathrm{t}$-value $=0.99$ ).

One interpretation of the finding that the high-skilled immigration shock has a larger impact on employment shares in narrow versus broad AI-related occupations is that the supply of skilled labor is a more binding constraint for former than for the latter. Relaxing this constraint would then generates larger adjustment in V.3 than in V.2 occupations. Because narrow V.3 job titles are associated with the more skilled jobs than the broad V.2 titles, this interpretation appears plausible. 
Table 4:

Long difference (2000-2018): Immigration Impact on CZ Specialization in AI-Related Occupations (V.2)

\begin{tabular}{|c|c|c|c|c|c|c|}
\hline & \multicolumn{3}{|c|}{ Men } & \multicolumn{3}{|c|}{ Women } \\
\hline & Foreign-born & Native-born & All & Foreign-born & Native-born & All \\
\hline & $(1)$ & $(2)$ & (3) & (4) & (5) & (6) \\
\hline Immigrant shock (v2) & $\begin{array}{c}0.989 \\
(0.260)\end{array}$ & $\begin{array}{c}0.217 \\
(0.278)\end{array}$ & $\begin{array}{c}1.206 \\
(0.476)\end{array}$ & $\begin{array}{c}0.280 \\
(0.283)\end{array}$ & $\begin{array}{c}0.119 \\
(0.153)\end{array}$ & $\begin{array}{r}0.400 \\
(0.352)\end{array}$ \\
\hline State FE & Yes & Yes & Yes & Yes & Yes & Yes \\
\hline Obs. & 722 & 722 & 722 & 717 & 717 & 717 \\
\hline Adj. R-squared & 0.675 & 0.478 & 0.398 & 0.637 & 0.534 & 0.466 \\
\hline DV Mean & 0.102 & -0.037 & 0.065 & 0.003 & -0.130 & -0.128 \\
\hline DV 25th percentile & 0.027 & -0.145 & -0.045 & -0.029 & -0.190 & -0.196 \\
\hline DV 75th percentile & 0.141 & 0.046 & 0.157 & 0.028 & -0.067 & -0.065 \\
\hline
\end{tabular}

The dependent variable is the change in the share of hours worked in AI-related occupations (V.2 definition) for the long difference 2000-2018 for men (columns 1-3) and women (4-6), shown separately for all workers (columns 5 and 6), foreign-born workers (columns 1 and 2), and native-born workers (columns 3 and 4). The immigrant shock for AI-related occupations (V.2 definition) is defined in equation (2). The sample is individuals 25 to 54 years old with at least a bachelor's degree residing in one of the 722 commuting zones in the continental US. All regressions include a constant, the summed product of the weights used in the immigration shock, state fixed effects, and initial-period shares of the college educated in the population, the foreign-born in the population, females in total employment, employment in manufacturing, employment in routine-intensive jobs, and employment in offshorable jobs. Standard errors (in parentheses) are clustered by state. Regressions are weighted by CZ employment (of prime-age, college educated workers of the designated gender) in the initial period. 


\section{Discussion}

The frenzy over artificial intelligence rivals that surrounding the space race of the 1950s and 1960s. With applications of AI still in its early stages, observers are free to make bold claims about how the technology will cause widespread job loss, usher in a future of driverless transportation, render language barriers obsolete, or bring forth other massive disruptions. Whatever the future of AI, it is likely to inspire heavy investments in new ventures for some time to come. Where these investments occur will help determine the future spatial distribution of activities in IT. Because AI is the current frontier of IT, which locations host its creation is of enormous interest to government and industry alike.

In the US, the regions that are best able to attract the computer scientists, data scientists, and computer systems engineers who are most adept at machine learning and related activities are likely to be the ones that acquire a comparative advantage in AI. Globalization has made it possible to obtain advanced computer hardware just about anywhere. Advances in digital communications now allow data to flow freely across space. Because these two key AI ingredients are footloose, the location of their production has little bearing on the location of AI production. The technical talent that creates AI is also footloose. In the US, much of this talent is foreign born-and from India and China in particular. The location choices of newly arrived immigrants, whether low-skilled or high-skilled, tend to follow the location choices of previous generations of workers from their origin countries. So too has it been in the case for AI-related workers. US commuting zones that were most exposed to increases in the supply of college-educated immigrants-based on the previous specialization patterns of these regions and their historical attraction to foreign-born arrivals-have seen the largest increase in the share of employment devoted to AI-related jobs. The lesson from this regularity is that access to high-skilled immigration relaxes the talent constraint that limits the expansion of AI. The US government, by regulating the volume and composition of high-skilled labor inflows from abroad, in effect regulates the pace of growth in AI.

The US model of innovation in AI-in which private-sector firms competing in open markets make their own investment decisions and hire talent from around the worldstands in contrast with that of China. China's tech firms enjoy protection from foreign competition, receive subsidies for $R \& D$, and benefit from the government's appetite for facial recognition and other AI applications. One presumes that the talent constraint in AI production applies in China, just as in the US. What remains to be seen is whether the relative openness of the US to immigration gives it an advantage in the sector. 


\section{References}

Abraham, Katharine G, Haltiwanger, John, Sandusky, Kristin, \& Spletzer, James. 2019. The rise of the gig economy: fact or fiction? Pages 357-61 of: AEA Papers and Proceedings, vol. 109.

Acemoglu, Daron, \& Restrepo, Pascual. 2020. Robots and jobs: Evidence from US labor markets. Journal of Political Economy, 128(6), 2188-2244.

Acemoglu, Daron, Autor, David, Hazell, Joe, Restrepo, Pascual, et al. 2020. AI and Jobs: Evidence from Online Vacancies. Tech. rept. National Bureau of Economic Research, Inc.

Allen, Greg, \& Chan, Taniel. 2017. Artificial intelligence and national security. Belfer Center for Science and International Affairs Cambridge, MA.

Altonji, Joseph G., \& Card, David. 1991. The Effects of Immigration on the Labor Market Outcomes of Less-skilled Natives. University of Chicago Press. Pages 201-234.

Atalay, Enghin, Phongthiengtham, Phai, Sotelo, Sebastian, \& Tannenbaum, Daniel. 2020. The Evolution of Work in the United States. American Economic Journal: Applied Economics, 12(2), 1-34.

Autor, David, Mindell, David, \& Reynolds, Elisabeth. 2020. The Work of the Future: Building Better Jobs in an Age of Intelligent Machines. MIT Work of the Future.

Autor, David H, \& Dorn, David. 2013. The growth of low-skill service jobs and the polarization of the US labor market. American Economic Review, 103(5), 1553-97.

Autor, David H, Dorn, David, \& Hanson, Gordon H. 2013. The China syndrome: Local labor market effects of import competition in the United States. American Economic Review, 103(6), 2121-68.

Bernstein, Shai, Diamond, Rebecca, McQuade, Timothy, Pousada, Beatriz, et al. 2018. The contribution of high-skilled immigrants to innovation in the United States. Standford Graduate School of Business Working Paper 3748, en, 202019-20.

Bloom, Nicholas, Hassan, Tarek Alexander, Kalyani, Aakash, Lerner, Josh, \& Tahoun, Ahmed. 2020. The Geography of New Technologies. Stanford mimeo.

Borjas, George J, \& Doran, Kirk B. 2012. The collapse of the Soviet Union and the productivity of American mathematicians. The Quarterly Journal of Economics, 127(3), 11431203. 
Borusyak, Kirill, Hull, Peter, \& Jaravel, Xavier. 2018. Quasi-experimental shift-share research designs. Tech. rept. National Bureau of Economic Research.

Bound, John, Khanna, Gaurav, \& Morales, Nicolas. 2017. Understanding the Economic Impact of the H-1B Program on the US. In: High-Skilled Migration to the United States and its Economic Consequences. University of Chicago Press.

Bound, John, Braga, Breno, Khanna, Gaurav, \& Turner, Sarah. 2021. The Globalization of Postsecondary Education: The Role of International Students in the US Higher Education System. Journal of Economic Perspectives, 35(1), 163-84.

Brynjolfsson, Erik, Mitchell, Tom, \& Rock, Daniel. 2018. What can machines learn, and what does it mean for occupations and the economy? Pages 43-47 of: AEA Papers and Proceedings, vol. 108.

Brynjolfsson, Erik, Mitchell, Tom, \& Rock, Daniel. 2019. Machine Learning and Occupational Change. Unpublished manuscript, MIT.

Burstein, Ariel, Hanson, Gordon, Tian, Lin, \& Vogel, Jonathan. 2020. Tradability and the Labor-Market Impact of Immigration: Theory and Evidence From the United States. Econometrica, 88(3), 1071-1112.

Card, David. 2001. Immigrant inflows, native outflows, and the local labor market impacts of higher immigration. Journal of Labor Economics, 19(1), 22-64.

Chatterji, Aaron, Glaeser, Edward, \& Kerr, William. 2014. Clusters of entrepreneurship and innovation. Innovation policy and the economy, 14(1), 129-166.

Chen, M Keith, Rossi, Peter E, Chevalier, Judith A, \& Oehlsen, Emily. 2019. The value of flexible work: Evidence from uber drivers. Journal of political economy, 127(6), 2735-2794.

Cockburn, Iain M, Henderson, Rebecca, \& Stern, Scott. 2018 (March). The Impact of Artificial Intelligence on Innovation. Working Paper 24449. National Bureau of Economic Research.

Deming, David J. 2017. The growing importance of social skills in the labor market. The Quarterly Journal of Economics, 132(4), 1593-1640.

Dorn, David. 2009. Essays on inequality, spatial interaction, and the demand for skills. Dissertation University of St. Gallen no. 3613. 
Dustmann, Christian, \& Fabbri, Francesca. 2003. Language proficiency and labour market performance of immigrants in the UK. The Economic Journal, 113(489), 695-717.

Felten, Edward, Raj, Manav, \& Seamans, Robert Channing. 2019. The effect of artificial intelligence on human labor: An ability-based approach. Page 15784 of: Academy of Management Proceedings, vol. 2019. Academy of Management Briarcliff Manor, NY 10510.

Felten, Edward W, Raj, Manav, \& Seamans, Robert. 2018. A method to link advances in artificial intelligence to occupational abilities. Pages 54-57 of: AEA Papers and Proceedings, vol. 108.

Goldfarb, Avi, \& Trefler, Daniel. 2018. Artificial intelligence and international trade. Pages 463-492 of: The Economics of Artificial Intelligence: An Agenda. University of Chicago Press.

Goos, Maarten, Manning, Alan, \& Salomons, Anna. 2014. Explaining job polarization: Routine-biased technological change and offshoring. American economic review, 104(8), 2509-26.

Grogger, Jeffrey, \& Hanson, Gordon H. 2011. Income maximization and the selection and sorting of international migrants. Journal of Development Economics, 95(1), 42-57.

Hanson, Gordon, \& Liu, Chen. 2021. Immigration and Occupational Comparative Advantage. Tech. rept. National Bureau of Economic Research.

Hanson, Gordon H, \& Liu, Chen. 2017. High-skilled immigration and the comparative advantage of foreign-born workers across us occupations. Pages 7-40 of: High-skilled migration to the United States and its economic consequences. University of Chicago Press.

Hanson, Gordon H, \& Slaughter, Matthew J. 2018. High-Skilled Immigration and the Rise of STEM Occupations in US Employment. Education, Skills, and Technical Change: Implications for Future US GDP Growth, 77, 465.

Hunt, Jennifer. 2011. Which immigrants are most innovative and entrepreneurial? Distinctions by entry visa. Journal of Labor Economics, 29(3), 417-457.

Hunt, Jennifer. 2015. Are Immigrants the Most Skilled US Computer and Engineering Workers? Journal of Labor Economics, 33(S1), S39-S77.

Hunt, Jennifer, \& Gauthier-Loiselle, Marjolaine. 2010. How much does immigration boost innovation? American Economic Journal: Macroeconomics, 2(2), 31-56. 
Katz, Lawrence F, \& Autor, David. 1999. Changes in the wage structure and earnings inequality. Pages 1463-1555 of: Handbook of labor economics, vol. 3. Elsevier.

Kerr, William R, \& Lincoln, William F. 2010. The supply side of innovation: H-1B visa reforms and US ethnic invention. Journal of Labor Economics, 28(3), 473-508.

Lazear, Edward P. 2021. Why are some immigrant groups more successful than others? Journal of Labor Economics, 39(1), 115-133.

Lin, Jeffrey. 2011. Technological adaptation, cities, and new work. Review of Economics and Statistics, 93(2), 554-574.

Moretti, Enrico. 2012. The new geography of jobs. Houghton Mifflin Harcourt.

Moretti, Enrico. 2019. The effect of high-tech clusters on the productivity of top inventors. Tech. rept. National Bureau of Economic Research.

Oreopoulos, Philip. 2011. Why Do Skilled Immigrants Struggle in the Labor Market? A Field Experiment with Thirteen Thousand Resumes. American Economic Journal: Economic Policy, 3(4), 148-71.

Patel, Krishna, \& Vella, Francis. 2013. Immigrant networks and their implications for occupational choice and wages. Review of Economics and Statistics, 95(4), 1249-1277.

Peri, Giovanni, \& Sparber, Chad. 2009. Task specialization, immigration, and wages. American Economic Journal: Applied Economics, 1(3), 135-169.

Peri, Giovanni, Shih, Kevin, \& Sparber, Chad. 2015. STEM workers, H-1B visas, and productivity in US cities. Journal of Labor Economics, 33(S1), S225-S255.

Taddy, Matt. 2018. The technological elements of artificial intelligence. Tech. rept. National Bureau of Economic Research.

Tolbert, Charles M, \& Sizer, Molly. 1996. US commuting zones and labor market areas: A 1990 update. ERS Staff Paper Number 9614. Washington, DC: Economic Research Service. Tech. rept. Rural Economy Division, US Department of Agriculture.

Varian, Hal. 2018. Artificial intelligence, economics, and industrial organization. Tech. rept. National Bureau of Economic Research.

Webb, Michael. 2020. The Impact of Articial Intelligence on the Labor Market. Unpublished manuscript, Stanford. 
Xie, Qingnan, \& Freeman, Richard B. 2020 (May). The Contribution of Chinese Diaspora Researchers to Global Science and China's Catching Up in Scientific Research. Working Paper 27169. National Bureau of Economic Research. 


\begin{tabular}{|c|c|c|c|}
\hline Occupation & Occupation Title & V.3 AI & New \\
\hline \multirow{32}{*}{$\begin{array}{l}\text { Computer } \\
\text { scientists } \\
\text { and systems } \\
\text { analysts }\end{array}$} & Analyst $\backslash$ n.s. & & \\
\hline & Artificial intelligence specialist & $\checkmark$ & $\checkmark$ \\
\hline & Business systems analyst & & \\
\hline & Computer analyst & & \\
\hline & Computer consultant $\backslash$ n.e.c. or n.s. & & \\
\hline & Computer research & $\checkmark$ & $\checkmark$ \\
\hline & Computer scientist & $\checkmark$ & \\
\hline & Computer systems analyst & & \\
\hline & Computer systems design analyst & $\checkmark$ & $\checkmark$ \\
\hline & Computer systems designer & $\checkmark$ & \\
\hline & Computer systems, planning & & \\
\hline & Computing systems analyst & & \\
\hline & Consultant, systems, computer or data processing & & \\
\hline & Data processing consultant & & \\
\hline & Data processing systems analyst & & \\
\hline & Data processing systems project planner & & \\
\hline & Digital computer systems analyst & & \\
\hline & Engineering systems analyst & & \\
\hline & Health systems analyst, computer & & \\
\hline & Information scientist & $\checkmark$ & \\
\hline & Information systems consultant & & \\
\hline & Information systems specialist & & \\
\hline & Information technology specialist, general or n.s. & & \\
\hline & Information technology specialist, systems analysis & & \\
\hline & Methods analyst, computer & & \\
\hline & Scientific systems analyst & & \\
\hline & Software consultant $\backslash$ n.e.c. & & \\
\hline & Supervisor, computer analyst & & \\
\hline & Systems analyst, computer systems & & \\
\hline & Systems analyst, data processing & & \\
\hline & Systems architect & & \\
\hline & Technician, computer or computer laboratory & & \\
\hline \multirow{35}{*}{$\begin{array}{l}\text { Computer } \\
\text { software } \\
\text { engineers }\end{array}$} & Applications developer & & \\
\hline & C.N.E. (certified Novell engineer) & $\checkmark$ & $\checkmark$ \\
\hline & Computer applications developer & & \\
\hline & Computer programmer analyst & & \\
\hline & Computer specialist, software & & \\
\hline & Engineer, Microsoft certified systems (MCSE) & $\checkmark$ & $\checkmark$ \\
\hline & Engineer, computer applications & $\checkmark$ & \\
\hline & Engineer, computer software $\backslash$ n.e.c. & $\checkmark$ & \\
\hline & Engineer, computer software applications & $\checkmark$ & $\checkmark$ \\
\hline & Engineer, computer software systems & $\checkmark$ & $\checkmark$ \\
\hline & Engineer, computer systems & $\checkmark$ & \\
\hline & Engineer, software $\backslash$ n.e.c. & $\checkmark$ & \\
\hline & Engineer, software applications & $\checkmark$ & $\checkmark$ \\
\hline & Engineer, software requirements & $\checkmark$ & $\checkmark$ \\
\hline & Engineer, software systems & $\checkmark$ & $\checkmark$ \\
\hline & Engineer, system & $\checkmark$ & \\
\hline & Engineer, system EDP & $\checkmark$ & $\checkmark$ \\
\hline & Engineer, systems analyst & $\checkmark$ & $\checkmark$ \\
\hline & Info. technology specialist, software engineering, applications & & \\
\hline & Inf. technology specialist, software engineering, systems & & \\
\hline & M.C.S.E (Microsoft certified systems engineer) & $\checkmark$ & $\checkmark$ \\
\hline & Program analyst & & \\
\hline & Programmer analyst & & \\
\hline & Quality assurance specialist, applications & & \\
\hline & Quality assurance specialist, systems software & & \\
\hline & Software QA tester & & \\
\hline & Software applications specialist & & \\
\hline & Software designer & $\checkmark$ & \\
\hline & Software developer & & \\
\hline & Software development specialist & & \\
\hline & Software installer & & \\
\hline & Software specialist, systems & & \\
\hline & Software writer & & \\
\hline & Supervisor, software engineering & & \\
\hline & Tester, software & & \\
\hline
\end{tabular}

\begin{tabular}{|c|c|c|c|}
\hline Occupation & Occupation Title & V.3 AI & New \\
\hline \multirow{29}{*}{$\begin{array}{l}\text { Network } \\
\text { systems and } \\
\text { data com- } \\
\text { munications } \\
\text { analysts }\end{array}$} & Chat room host/monitor & & \\
\hline & Communications consultant & & \\
\hline & Computer consultant, networks & & \\
\hline & Computer integration & & \\
\hline & Data communications analyst & & \\
\hline & Engineer, network & & \\
\hline & Info. technology specialist, internet & & \\
\hline & Info. technology specialist, network services & & \\
\hline & Internet developer & & \\
\hline & Intranet developer & & \\
\hline & Manager, website & & \\
\hline & Multimedia telecom. systems integrator & & \\
\hline & Network analyst & & \\
\hline & Network architect & & \\
\hline & Network consultant & & \\
\hline & Network designer & $\checkmark$ & $\checkmark$ \\
\hline & Network specialist & & \\
\hline & Network support & & \\
\hline & Network systems analyst & & \\
\hline & Network systems integrator & & \\
\hline & Software consultant, data communications & & \\
\hline & Software consultant, networks & & \\
\hline & Systems integrator & & \\
\hline & Systems planner & & \\
\hline & Telecommunications specialist & & \\
\hline & Web designer & $\checkmark$ & $\checkmark$ \\
\hline & Web developer & & \\
\hline & Web specialist & & \\
\hline & Webmaster & & \\
\hline \multirow{10}{*}{ Statisticians } & Analytical statistician & & \\
\hline & Applied statistician & & \\
\hline & Biometrician & $\checkmark$ & \\
\hline & Biostatistician & $\checkmark$ & \\
\hline & Engineer, statistical & $\checkmark$ & \\
\hline & Mathematical statistician & & \\
\hline & Sampling expert & & \\
\hline & Statistician & & \\
\hline & Survey statistician & & \\
\hline & Time study statistician & & \\
\hline \multirow{8}{*}{$\begin{array}{l}\text { Computer } \\
\text { hardware } \\
\text { engineers }\end{array}$} & Computer designer & & \\
\hline & Computer layout & & \\
\hline & Computer tester & & \\
\hline & Engineer, computer $\backslash$ n.e.c. or n.s. & $\checkmark$ & $\checkmark$ \\
\hline & Engineer, computer hardware & $\checkmark$ & \\
\hline & Engineer, design $\backslash$ n.s. & $\checkmark$ & \\
\hline & Engineer, installation, computers exc. PCs & & \\
\hline & Microchip specialist & & \\
\hline
\end{tabular}

Table A.1: Job Titles Associated with AI-Related Occupations (V.3 definition) This table lists all occupation titles that correspond to Census occupation codes that have at least one AIrelated title by the V.3 definition. Column 3 indicates whether a title is AI-related; column 4 indicates whether the title was added after 1990. 


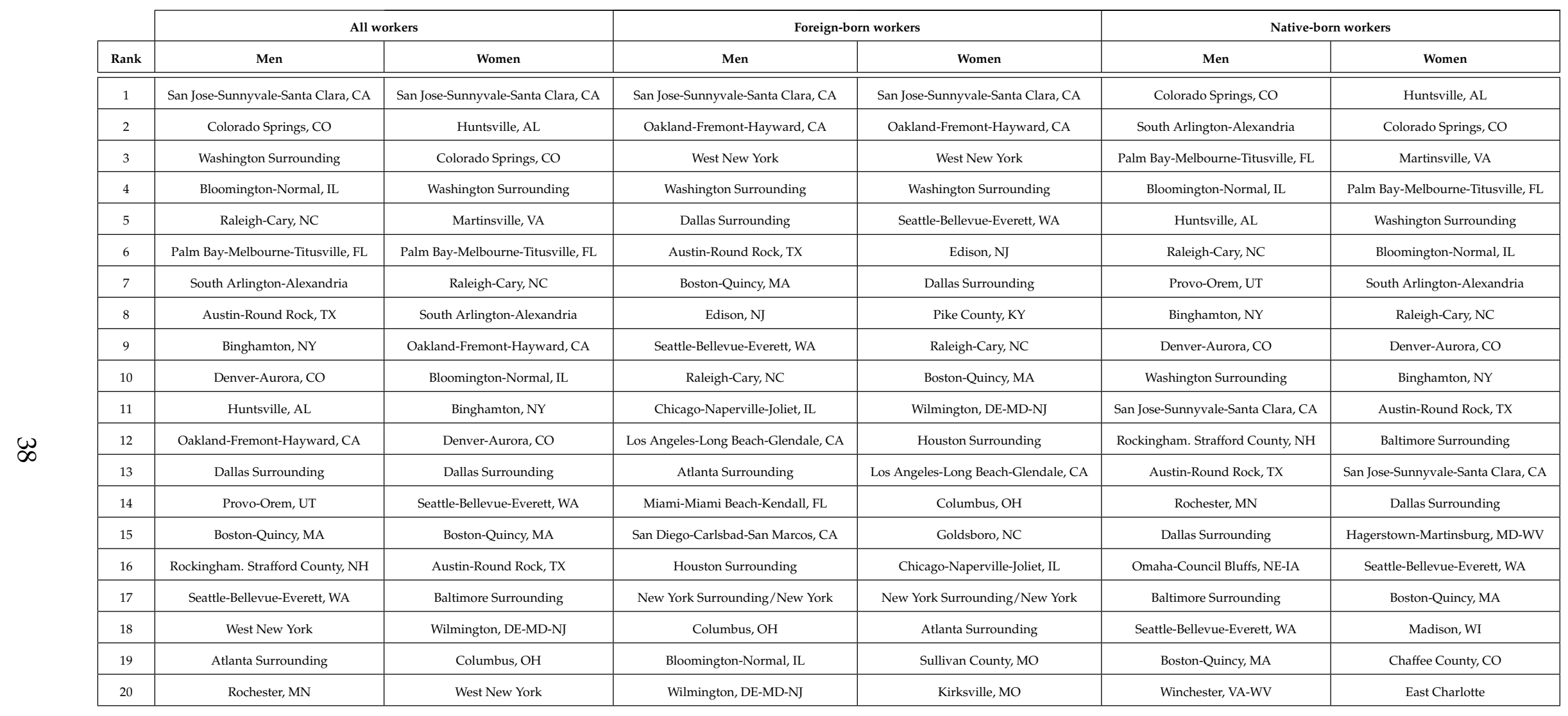

\section{Table A.2: Top 20 CZ's in Terms of Share of CZ Hours Worked in AI-Related Occupations, 2000}

This table reports the top 20 commuting zones in terms of the share of CZ hours worked in AI-related occupations (V.3 definition) for prime-age, college-educated men and women in 2000. AI hours worked is measured as hours worked in a given AI-related occupation times the share of all 2000 jobs titles in that occupation that were created after 1990 and that were AI-related. 


\begin{tabular}{|c|c|c|c|c|c|c|}
\hline & \multicolumn{2}{|c|}{ All workers } & \multicolumn{2}{|c|}{ Foreign-born workers } & \multicolumn{2}{|c|}{ Native-born workers } \\
\hline Rank & Men & Women & Men & Women & Men & Women \\
\hline 1 & Washington Surrounding & Washington Surrounding & San Jose-Sunnyvale-Santa Clara, CA & San Jose-Sunnyvale-Santa Clara, CA & Washington Surrounding & Washington Surrounding \\
\hline 2 & Los Angeles-Long Beach-Glendale, CA & Oakland-Fremont-Hayward, CA & Oakland-Fremont-Hayward, CA & Oakland-Fremont-Hayward, CA & Boston-Quincy, MA & Boston-Quincy, MA \\
\hline 3 & Oakland-Fremont-Hayward, CA & Chicago-Naperville-Joliet, IL & West New York & Washington Surrounding & Chicago-Naperville-Joliet, IL & Chicago-Naperville-Joliet, IL \\
\hline 4 & Chicago-Naperville-Joliet, IL & Boston-Quincy, MA & Los Angeles-Long Beach-Glendale, CA & West New York & Los Angeles-Long Beach-Glendale, CA & New York Surrounding/New York \\
\hline 5 & San Jose-Sunnyvale-Santa Clara, CA & New York Surrounding/New York & Washington Surrounding & Los Angeles-Long Beach-Glendale, CA & Oakland-Fremont-Hayward, CA & Oakland-Fremont-Hayward, CA \\
\hline 6 & Boston-Quincy, MA & Los Angeles-Long Beach-Glendale, CA & New York Surrounding/New York & New York Surrounding/New York & New York Surrounding/New York & Los Angeles-Long Beach-Glendale, CA \\
\hline 7 & West New York & West New York & Chicago-Naperville-Joliet, IL & Chicago-Naperville-Joliet, IL & Atlanta Surrounding & West New York \\
\hline 8 & New York Surrounding/New York & San Jose-Sunnyvale-Santa Clara, CA & Boston-Quincy, MA & Boston-Quincy, MA & Denver-Aurora, $\mathrm{CO}$ & Atlanta Surrounding \\
\hline 9 & Atlanta Surrounding & Atlanta Surrounding & Dallas Surrounding & Seattle-Bellevue-Everett, WA & West New York & Philadelphia, PA \\
\hline 10 & Dallas Surrounding & Seattle-Bellevue-Everett, WA & Seattle-Bellevue-Everett, WA & Dallas Surrounding & Seattle-Bellevue-Everett, WA & Denver-Aurora, CO \\
\hline 11 & Seattle-Bellevue-Everett, WA & Philadelphia, PA & Atlanta Surrounding & Atlanta Surrounding & Dallas Surrounding & Seattle-Bellevue-Everett, WA \\
\hline 12 & Denver-Aurora, CO & Dallas Surrounding & Houston Surrounding & Houston Surrounding & San Jose-Sunnyvale-Santa Clara, CA & Warren-Farmington Hills-Troy, MI \\
\hline 13 & Philadelphia, PA & Warren-Farmington Hills-Troy, MI & Warren-Farmington Hills-Troy, MI & Philadelphia, PA & Philadelphia, PA & Dallas Surrounding \\
\hline 14 & Minneapolis-Bloomington, MN-WI & Denver-Aurora, CO & Philadelphia, PA & Warren-Farmington Hills-Troy, MI & Minneapolis-Bloomington, MN-WI & Minneapolis-Bloomington, MN-WI \\
\hline 15 & Warren-Farmington Hills-Troy, MI & Minneapolis-Bloomington, MN-WI & Miami-Miami Beach-Kendall, FL & Miami-Miami Beach-Kendall, FL & Warren-Farmington Hills-Troy, MI & Baltimore Surrounding \\
\hline 16 & Houston Surrounding & Houston Surrounding & San Diego-Carlsbad-San Marcos, CA & Minneapolis-Bloomington, MN-WI & Baltimore Surrounding, & Houston Surrounding \\
\hline 17 & Raleigh-Cary, NC & Baltimore Surrounding & Minneapolis-Bloomington, MN-WI & Raleigh-Cary, NC & Houston Surrounding & San Jose-Sunnyvale-Santa Clara, CA \\
\hline 18 & Baltimore Surrounding & Raleigh-Cary, NC & Denver-Aurora, CO & San Diego-Carlsbad-San Marcos, CA & Raleigh-Cary, NC & Raleigh-Cary, NC \\
\hline 19 & Hartford, CT & Hartford, CT & Austin-Round Rock, TX & Hartford, CT & Hartford CT & Hartford, CT \\
\hline 20 & San Diego-Carlsbad-San Marcos, CA & Phoenix-Mesa-Scottsdale, AZ & Hartford, CT & Baltimore Surrounding & Phoenix-Mesa-Scottsdale, AZ & Phoenix-Mesa-Scottsdale, AZ \\
\hline
\end{tabular}

\section{Table A.3: Top 20 Commuting Zones in Terms of CZ Share of National Hours Worked in AI-Related Occupations}

This table reports the top 20 commuting zones in terms of the CZ share of national hours worked in AI-related occupations (V.3 definition) for prime-age, college-educated men and women in 2000. AI hours worked is measured as hours worked in a given AI-related occupation times the share of all 2000 jobs titles in that occupation that were created after 1990 and that were AI-related. 
Table A.4: Share of Hours Worked in All Occupations among Prime-Age, College-educated Workers by Region of Birth

\begin{tabular}{lccc}
\hline \hline & & & \\
& 2000 & $2004-09$ & $2014-18$ \\
\cline { 2 - 4 } Men & & & \\
Native born & 86.5 & 83.1 & 81.5 \\
Latin America + Caribbean & 2.5 & 3.7 & 3.9 \\
Africa and Middle East & 1.4 & 1.8 & 2.1 \\
China + Hong Kong & 0.9 & 1.2 & 1.4 \\
India & 2.1 & 3.1 & 4.3 \\
Korea + Japan + Taiwan & 1.3 & 1.4 & 1.3 \\
Other Asia & 1.9 & 2.2 & 2.1 \\
Europe + Australia + New Zealand + Canada & 3.4 & 3.6 & 3.5 \\
Women & & & \\
Native born & 88.4 & 85.6 & 84.5 \\
Latin America + Caribbean & 2.5 & 3.6 & 4.0 \\
Africa and Middle East & 0.7 & 0.9 & 1.2 \\
China + Hong Kong & 0.9 & 1.2 & 1.4 \\
India & 1.1 & 1.6 & 2.2 \\
Korea + Japan + Taiwan & 1.1 & 1.3 & 1.1 \\
Other Asia & 2.5 & 2.7 & 2.5 \\
Europe + Australia + New Zealand + Canada & 2.7 & 3.1 & 3.0 \\
\hline
\end{tabular}

Each cell reports the fraction of hours worked by a particular national origin group for men and women with at least a college education and who are 25 to 54 years old. The data are from the 2000 Census and the 2005-2009 and 2014-2018 five-year ACS samples. 
Table A.5: Share of Hours Worked in V.0 and V.1 Occupations among Prime-Age, College-educated Workers by Region of Birth

\begin{tabular}{lccc|ccc}
\hline \hline & \multicolumn{3}{c}{ V.0 Hours } & \multicolumn{3}{c}{ V.1 Hours } \\
& 2000 & $2004-09$ & $2014-18$ & 2000 & $2004-09$ & $2014-18$ \\
\cline { 2 - 7 } Men & & & & & & \\
Native born & 80.2 & 75.7 & 72.9 & 78.8 & 74.2 & 71.4 \\
Latin America + Caribbean & 1.9 & 2.5 & 3.0 & 1.9 & 2.4 & 2.9 \\
Africa and Middle East & 1.5 & 1.8 & 2.1 & 1.5 & 1.7 & 2.1 \\
China + Hong Kong & 2.1 & 2.5 & 2.7 & 2.4 & 2.8 & 2.9 \\
India & 5.0 & 7.8 & 10.9 & 5.7 & 8.9 & 12.1 \\
Korea + Japan + Taiwan & 1.7 & 1.9 & 1.5 & 1.8 & 2.0 & 1.6 \\
Other Asia & 2.9 & 3.2 & 2.6 & 3.0 & 3.3 & 2.7 \\
Europe + Australia + New Zealand + Canada & 4.6 & 4.7 & 4.3 & 4.8 & 4.7 & 4.3 \\
Women & & & & & & \\
Native born & 80.6 & 75.9 & 73.1 & 79.0 & 73.9 & 71.8 \\
Latin America + Caribbean & 2.0 & 2.7 & 3.0 & 2.0 & 2.8 & 3.1 \\
Africa and Middle East & 0.8 & 1.1 & 1.3 & 0.8 & 1.2 & 1.3 \\
China + Hong Kong & 3.5 & 4.2 & 4.3 & 4.0 & 4.7 & 4.5 \\
India & 3.3 & 6.0 & 9.3 & 3.8 & 7.0 & 10.2 \\
Korea + Japan + Taiwan & 2.3 & 2.1 & 1.6 & 2.6 & 2.3 & 1.7 \\
Other Asia & 3.3 & 3.6 & 3.3 & 3.4 & 3.9 & 3.5 \\
Europe + Australia + New Zealand + Canada & 4.2 & 4.4 & 4.0 & 4.2 & 4.4 & 3.8 \\
\hline
\end{tabular}

Each cell reports the fraction of hours worked by a particular national origin group for men and women with at least a college education and who are 25 to 54 years old in V.0 or V.1 occupations. Data are from the 2000 Census and the 2005-2009 and 2014-2018 five-year ACS samples. 
Table A.6: Share of Hours Worked in V.2 and V.3 Occupations among Prime-Age, College-educated Workers by Region of Birth

\begin{tabular}{lccc|ccc}
\hline \hline & \multicolumn{3}{c}{ V.2 Hours } & \multicolumn{3}{c}{ V.3 Hours } \\
& 2000 & $2004-09$ & $2014-18$ & 2000 & $2004-09$ & $2014-18$ \\
\cline { 2 - 7 } Men & & & & & & \\
Native born & 76.6 & 71.3 & 67.5 & 75.2 & 68.8 & 65.2 \\
Latin America + Caribbean & 2.0 & 2.4 & 2.9 & 2.1 & 2.4 & 3.0 \\
Africa and Middle East & 1.6 & 1.8 & 2.2 & 1.6 & 1.9 & 2.3 \\
China + Hong Kong & 2.7 & 3.2 & 3.4 & 3.0 & 3.3 & 3.4 \\
India & 6.6 & 10.4 & 14.6 & 7.8 & 12.6 & 16.9 \\
Korea + Japan + Taiwan & 2.0 & 2.2 & 1.7 & 2.0 & 2.1 & 1.6 \\
Other Asia & 3.4 & 3.6 & 3.1 & 3.4 & 3.7 & 3.0 \\
Europe + Australia + New Zealand + Canada & 5.2 & 5.2 & 4.6 & 5.0 & 5.2 & 4.7 \\
Women & & & & & & \\
Native born & 76.4 & 70.3 & 65.1 & 78.1 & 70.8 & 65.1 \\
Latin America + Caribbean & 1.9 & 2.2 & 2.8 & 1.9 & 2.2 & 2.7 \\
Africa and Middle East & 0.9 & 1.2 & 1.4 & 0.8 & 1.2 & 1.4 \\
China + Hong Kong & 4.9 & 5.7 & 5.6 & 4.5 & 5.5 & 5.3 \\
India & 4.7 & 9.2 & 15.4 & 4.8 & 10.2 & 16.4 \\
Korea + Japan + Taiwan & 2.9 & 2.4 & 1.8 & 2.8 & 2.2 & 1.8 \\
Other Asia & 3.6 & 4.3 & 4.1 & 3.4 & 3.9 & 3.8 \\
Europe + Australia + New Zealand + Canada & 4.7 & 4.7 & 3.9 & 3.7 & 4.0 & 3.6 \\
\hline
\end{tabular}

Each cell reports the fraction of hours worked by a particular national origin group for men and women with at least a college education and who are 25 to 54 years old in V.2 or V.3 occupations. Data are from the 2000 Census and the 2005-2009 and 2014-2018 five-year ACS samples. 
Table A.7: Revealed Comparative Advantage in V.0 and V.1 Occupations by Worker Region of Birth

\begin{tabular}{lccc|ccc}
\hline \hline & \multicolumn{3}{c}{ V.0 Hours } & \multicolumn{3}{c}{ V.1 Hours } \\
Men & 2000 & $2004-09$ & $2014-18$ & 2000 & $2004-09$ & $2014-18$ \\
\cline { 2 - 7 } Native born & & & & & & \\
Latin America + Caribbean & -0.08 & -0.09 & -0.11 & -0.09 & -0.11 & -0.13 \\
Africa and Middle East & -0.27 & -0.39 & -0.26 & -0.25 & -0.42 & -0.28 \\
China + Hong Kong & 0.05 & -0.00 & -0.01 & 0.03 & -0.04 & -0.01 \\
India & 0.82 & 0.76 & 0.67 & 0.94 & 0.85 & 0.75 \\
Korea + Japan + Taiwan & 0.89 & 0.94 & 0.93 & 1.02 & 1.07 & 1.04 \\
Other Asia & 0.29 & 0.28 & 0.19 & 0.36 & 0.33 & 0.23 \\
Europe + Australia + New Zealand + Canada & 0.44 & 0.36 & 0.23 & 0.48 & 0.39 & 0.25 \\
Women & 0.30 & 0.26 & 0.20 & 0.34 & 0.28 & 0.20 \\
Native born & & & & & & \\
Latin America + Caribbean & -0.09 & -0.12 & -0.15 & -0.11 & -0.15 & -0.16 \\
Africa and Middle East & -0.23 & -0.28 & -0.26 & -0.22 & -0.26 & -0.25 \\
China + Hong Kong & 0.17 & 0.17 & 0.12 & 0.19 & 0.20 & 0.12 \\
India & 1.35 & 1.29 & 1.10 & 1.49 & 1.39 & 1.13 \\
Korea + Japan + Taiwan & 1.08 & 1.35 & 1.43 & 1.23 & 1.50 & 1.53 \\
Other Asia & 0.70 & 0.51 & 0.36 & 0.83 & 0.60 & 0.43 \\
Europe + Australia + New Zealand + Canada & 0.28 & 0.27 & 0.27 & 0.34 & 0.35 & 0.32 \\
\hline
\end{tabular}

Calculation is:

$$
R C A_{\text {kgst }}=\ln \left(\frac{\sum_{o \in \mathcal{O}^{v}}\left(L_{k g o s t}\right) / \sum_{o \in \mathcal{O}^{v}}\left(L_{\text {gost }}\right)}{\sum_{o \in \mathcal{O}}\left(L_{k g o s t}\right) / \sum_{o \in \mathcal{O}}\left(L_{\text {gost }}\right)}\right)
$$

where $L$ is hours worked and $\mathcal{O}^{v}$ is the set of occupations with a positive share of new STEM or potential AI work according to V.0 or V.1. This is calculated for each year $(t)$, gender $(g)$, and national origin group $(k)$ among either men or women 25 to 54 years old with at least a college education. Data are from the 2000 Census and the 2005-2009 and 2014-2018 five-year ACS samples. 
Table A.8: Revealed Comparative Advantage in V.2 and V.3 Occupations by Worker Region of Birth

\begin{tabular}{lccc|ccc}
\hline \hline & \multicolumn{3}{c}{ V.2 Hours } & \multicolumn{3}{c}{ V.3 Hours } \\
& 2000 & $2004-09$ & $2014-18$ & 2000 & $2004-09$ & $2014-18$ \\
\cline { 2 - 7 } Men & & & & & & \\
Native born & -0.12 & -0.15 & -0.19 & -0.14 & -0.19 & -0.22 \\
Latin America + Caribbean & -0.21 & -0.43 & -0.27 & -0.18 & -0.42 & -0.27 \\
Africa and Middle East & 0.09 & 0.02 & 0.04 & 0.11 & 0.07 & 0.08 \\
China + Hong Kong & 1.06 & 0.99 & 0.90 & 1.14 & 1.03 & 0.90 \\
India & 1.15 & 1.22 & 1.22 & 1.33 & 1.42 & 1.37 \\
Korea + Japan + Taiwan & 0.46 & 0.42 & 0.31 & 0.48 & 0.38 & 0.25 \\
Other Asia & 0.58 & 0.48 & 0.37 & 0.58 & 0.52 & 0.36 \\
Europe + Australia + New Zealand + Canada & 0.43 & 0.37 & 0.26 & 0.38 & 0.37 & 0.27 \\
Women & & & & & & \\
Native born & -0.15 & -0.20 & -0.26 & -0.12 & -0.19 & -0.26 \\
Latin America + Caribbean & -0.27 & -0.48 & -0.35 & -0.29 & -0.50 & -0.40 \\
Africa and Middle East & 0.21 & 0.26 & 0.18 & 0.20 & 0.25 & 0.17 \\
China + Hong Kong & 1.67 & 1.59 & 1.35 & 1.60 & 1.56 & 1.29 \\
India & 1.45 & 1.77 & 1.94 & 1.47 & 1.87 & 2.00 \\
Korea + Japan + Taiwan & 0.95 & 0.65 & 0.46 & 0.89 & 0.56 & 0.46 \\
Other Asia & 0.38 & 0.44 & 0.47 & 0.32 & 0.35 & 0.40 \\
Europe + Australia + New Zealand + Canada & 0.54 & 0.42 & 0.26 & 0.29 & 0.26 & 0.19 \\
\hline
\end{tabular}

Calculation is:

$$
R C A_{\text {kgst }}=\ln \left(\frac{\sum_{o \in \mathcal{O}^{v}}\left(L_{k g o s t}\right) / \sum_{o \in \mathcal{O}^{v}}\left(L_{\text {gost }}\right)}{\sum_{o \in \mathcal{O}}\left(L_{k g o s t}\right) / \sum_{o \in \mathcal{O}}\left(L_{\text {gost }}\right)}\right)
$$

where $L$ is hours worked and $\mathcal{O}^{v}$ is the set of occupations with a positive share of new STEM or potential AI work according to V.2 or V.3. This is calculated for each year $(t)$, gender $(g)$, and national origin group $(k)$ among either men or women 25 to 54 years old with at least a college education. Data are from the 2000 Census and the 2005-2009 and 2014-2018 five-year ACS samples. 
Table A.9: Summary Statistics for Dependent Variables and Immigration Shocks

\begin{tabular}{|c|c|c|c|c|c|}
\hline Variable & Obs & Mean & Std. Dev. & P25 & P75 \\
\hline \multicolumn{6}{|l|}{ Male hours worked } \\
\hline \multicolumn{6}{|l|}{ V.3 } \\
\hline All & 722 & .139 & .078 & .107 & .167 \\
\hline Foreign born & 722 & .076 & .073 & .032 & .088 \\
\hline Native born & 722 & .063 & .052 & .026 & .09 \\
\hline Immigrant shock & 722 & .052 & .035 & .027 & .076 \\
\hline \multicolumn{6}{|l|}{$\mathrm{V} .2$} \\
\hline All & 722 & .065 & .178 & -.045 & .157 \\
\hline Foreign born & 722 & .102 & .131 & .027 & .141 \\
\hline Native born & 722 & -.037 & .158 & -.145 & .046 \\
\hline Immigrant shock & 722 & .153 & .101 & .078 & .219 \\
\hline \multicolumn{6}{|l|}{ Male employment } \\
\hline \multicolumn{6}{|l|}{ V.3 } \\
\hline All & 722 & .144 & .08 & .113 & .173 \\
\hline Foreign born & 722 & .08 & .076 & .033 & .096 \\
\hline Native born & 722 & .064 & .054 & .024 & .094 \\
\hline Immigrant shock & 722 & .068 & .045 & .035 & .101 \\
\hline \multicolumn{6}{|l|}{ V.2 } \\
\hline All & 722 & .058 & .187 & -.055 & .155 \\
\hline Foreign born & 722 & .106 & .139 & .028 & .157 \\
\hline Native born & 722 & -.048 & .166 & -.156 & .035 \\
\hline Immigrant shock & 722 & .2 & .131 & .104 & .296 \\
\hline \multicolumn{6}{|l|}{$\begin{array}{l}\text { Female hours } \\
\text { worked }\end{array}$} \\
\hline \multicolumn{6}{|l|}{ V.3 } \\
\hline All & 722 & .001 & .033 & -.02 & .017 \\
\hline Foreign born & 722 & .019 & .022 & .005 & .027 \\
\hline Native born & 722 & -.018 & .032 & -.04 & -.002 \\
\hline Immigrant shock & 717 & .032 & .024 & .014 & .048 \\
\hline \multicolumn{6}{|l|}{$\mathrm{V} .2$} \\
\hline All & 722 & -.128 & .104 & -.196 & -.065 \\
\hline Foreign born & 722 & .003 & .053 & -.029 & .028 \\
\hline Native born & 722 & -.13 & .098 & -.19 & -.067 \\
\hline Immigrant shock & 717 & .114 & .084 & .049 & .168 \\
\hline \multicolumn{6}{|l|}{ Female employment } \\
\hline \multicolumn{6}{|l|}{ V.3 } \\
\hline All & 722 & .005 & .031 & -.015 & .02 \\
\hline Foreign born & 722 & .019 & .022 & .006 & .026 \\
\hline Native born & 722 & -.015 & .031 & -.034 & 0 \\
\hline Immigrant shock & 717 & .034 & .025 & .015 & .051 \\
\hline \multicolumn{6}{|l|}{ V.2 } \\
\hline All & 722 & -.115 & .101 & -.18 & -.053 \\
\hline Foreign born & 722 & .005 & .054 & -.023 & .029 \\
\hline Native born & 722 & -.12 & .094 & -.173 & -.063 \\
\hline Immigrant shock & 717 & .118 & .088 & .052 & .176 \\
\hline
\end{tabular}

This table reports means of the outcome variables and immigration shocks used in the regression analysis. The outcomes are changes employment shares (hours worked, worker counts) by gender group (male, female) in AI-related occupations (V.3, V.2) by nativity group (all workers, foreign-born, native-born) over 2000 to 2018. The immigration shock (defined in equation (2)) is the projected change in the supply of workers (by gender, employment definition) in AI-related occupations (by AI definition) relative to total initial-period labor supply in the CZ over 2000 to 2018. All variables are multiplied by 100 and decadalized (multiplied by 10 divided by the number of years between time periods). The sample includes individuals 25 to 54 years old with at least a bachelor's degree. Results are weighted using CZ total employment of prime-age, college-educated workers of the gender group in the initial period. 
Table A.10:

Long difference (2000-2018): Immigration Impact on CZ Specialization in AI-Related Occupations (V.3)

\begin{tabular}{|c|c|c|c|c|c|c|}
\hline & \multicolumn{3}{|c|}{ Men } & \multicolumn{3}{|c|}{ Women } \\
\hline & Foreign-born & Native-born & All & Foreign-born & Native-born & All \\
\hline & (1) & (2) & (3) & (4) & (5) & (6) \\
\hline Immigrant shock (v3) & $\begin{array}{c}1.529 \\
(0.341)\end{array}$ & $\begin{array}{l}-0.269 \\
(0.267)\end{array}$ & $\begin{array}{c}1.259 \\
(0.553)\end{array}$ & $\begin{array}{c}0.872 \\
(0.373)\end{array}$ & $\begin{array}{c}0.027 \\
(0.220)\end{array}$ & $\begin{array}{c}0.899 \\
(0.561)\end{array}$ \\
\hline State FE & Yes & Yes & Yes & Yes & Yes & Yes \\
\hline Obs. & 722 & 722 & 722 & 717 & 717 & 717 \\
\hline Adj. R-squared & 0.787 & 0.397 & 0.520 & 0.705 & 0.544 & 0.319 \\
\hline DV Mean & 0.080 & 0.064 & 0.144 & 0.019 & -0.015 & 0.005 \\
\hline DV 25th percentile & 0.033 & 0.024 & 0.113 & 0.006 & -0.034 & -0.015 \\
\hline DV 75th percentile & 0.096 & 0.094 & 0.173 & 0.026 & -0.000 & 0.020 \\
\hline
\end{tabular}

The dependent variable is the change in the share of workers employed in AI-related occupations (V.3 definition) for the long difference 2000-2018 for men (columns 1-3) and women (4-6), shown separately for all workers (columns 5 and 6), foreign-born workers (columns 1 and 2), and native-born workers (columns 3 and 4). The immigrant shock for AI-related occupations (V.3 definition) is defined in equation (2). The sample is individuals 25 to 54 years old with at least a bachelor's degree residing in one of the 722 commuting zones in the continental US. All regressions include a constant, the summed product of the weights used in the immigration shock, state fixed effects, and initial-period shares of the college educated in the population, the foreign-born in the population, females in total employment, employment in manufacturing, employment in routine-intensive jobs, and employment in offshorable jobs. Standard errors (in parentheses) are clustered by state. Regressions are weighted by CZ employment (of prime-age, college educated workers of the designated gender) in the initial period. 
Table A.11:

Long difference (2000-2018): Immigration Impact on CZ Specialization in AI-Related Occupations (V.2)

\begin{tabular}{|c|c|c|c|c|c|c|}
\hline & \multicolumn{3}{|c|}{ Men } & \multicolumn{3}{|c|}{ Women } \\
\hline & Foreign-born & Native-born & All & Foreign-born & Native-born & All \\
\hline & (1) & (2) & (3) & (4) & (5) & (6) \\
\hline Immigrant shock (v2) & $\begin{array}{c}0.763 \\
(0.224)\end{array}$ & $\begin{array}{c}0.088 \\
(0.247)\end{array}$ & $\begin{array}{c}0.851 \\
(0.422)\end{array}$ & $\begin{array}{c}0.382 \\
(0.270)\end{array}$ & $\begin{array}{c}0.091 \\
(0.145)\end{array}$ & $\begin{array}{c}0.473 \\
(0.334)\end{array}$ \\
\hline State FE & Yes & Yes & Yes & Yes & Yes & Yes \\
\hline Obs. & 722 & 722 & 722 & 717 & 717 & 717 \\
\hline Adj. R-squared & 0.667 & 0.494 & 0.390 & 0.648 & 0.530 & 0.476 \\
\hline DV Mean & 0.106 & -0.048 & 0.058 & 0.005 & -0.120 & -0.115 \\
\hline DV 25th percentile & 0.028 & -0.156 & -0.055 & -0.023 & -0.173 & -0.180 \\
\hline DV 75th percentile & 0.157 & 0.035 & 0.155 & 0.029 & -0.063 & -0.053 \\
\hline
\end{tabular}

The dependent variable is the change in the share of workers employed in AI-related occupations (V.2 definition) for the long difference 2000-2018 for men (columns 1-3) and women (4-6), shown separately for all workers (columns 5 and 6), foreign-born workers (columns 1 and 2), and native-born workers (columns 3 and 4). The immigrant shock for AI-related occupations (V.2 definition) is defined in equation (2). The sample is individuals 25 to 54 years old with at least a bachelor's degree residing in one of the 722 commuting zones in the continental US. All regressions include a constant, the summed product of the weights used in the immigration shock, state fixed effects, and initial-period shares of the college educated in the population, the foreign-born in the population, females in total employment, employment in manufacturing, employment in routine-intensive jobs, and employment in offshorable jobs. Standard errors (in parentheses) are clustered by state. Regressions are weighted by CZ employment (of prime-age, college educated workers of the designated gender) in the initial period. 
Table A.12:

Stacked first differences (2000-2009 and 2009-2018): Immigration Impact on CZ Specialization in AIRelated Occupations (V.3)

$$
D V: 100 \times \frac{10}{\Delta t} \times \Delta \frac{A I(v 3) \text { hours worked by nativity group }}{\text { total hours worked }}
$$

\begin{tabular}{|c|c|c|c|c|c|c|}
\hline & \multicolumn{3}{|c|}{ Men } & \multicolumn{3}{|c|}{ Women } \\
\hline & Foreign-born & Native-born & All & Foreign-born & Native-born & All \\
\hline & (1) & $(2)$ & (3) & $(4)$ & (5) & (6) \\
\hline Immigrant shock (v3) & $\begin{array}{c}1.835 \\
(0.260)\end{array}$ & $\begin{array}{l}-0.203 \\
(0.232)\end{array}$ & $\begin{array}{c}1.631 \\
(0.444)\end{array}$ & $\begin{array}{c}0.729 \\
(0.242)\end{array}$ & $\begin{array}{c}0.285 \\
(0.181)\end{array}$ & $\begin{array}{c}1.014 \\
(0.369)\end{array}$ \\
\hline State $\times$ Year FE & Yes & Yes & Yes & Yes & Yes & Yes \\
\hline Obs. & 1444 & 1444 & 1444 & 1438 & 1438 & 1438 \\
\hline Adj. R-squared & 0.719 & 0.453 & 0.564 & 0.550 & 0.420 & 0.388 \\
\hline DV Mean & 0.092 & 0.112 & 0.203 & 0.023 & 0.002 & 0.025 \\
\hline DV 25th percentile & 0.031 & 0.065 & 0.142 & 0.004 & -0.019 & -0.005 \\
\hline DV 75th percentile & 0.109 & 0.139 & 0.244 & 0.034 & 0.022 & 0.044 \\
\hline
\end{tabular}

The dependent variable is the change in the share of hours worked in AI-related occupations (V.3 definition) for stacked first differences over 2000-2009 and 2009-2018 for men (columns 1-3) and women (4-6), shown separately for all workers (columns 5 and 6), foreign-born workers (columns 1 and 2), and native-born workers (columns 3 and 4). The immigrant shock for AI-related occupations (V.3 definition) is defined in equation (2). The sample is individuals 25 to 54 years old with at least a bachelor's degree residing in one of the 722 commuting zones in the continental US. All regressions include a constant, the summed product of the weights used in the immigration shock, state fixed effects, and initial-period shares of the college educated in the population, the foreign-born in the population, females in total employment, employment in manufacturing, employment in routine-intensive jobs, and employment in offshorable jobs. Standard errors (in parentheses) are clustered by state. Regressions are weighted by $\mathrm{CZ}$ employment (of prime-age, college educated workers of the designated gender) in the initial period. 
Table A.13:

Stacked first differences (2000-2009 and 2009-2018): Immigration Impact on CZ Specialization in AIRelated Occupations (V.2)

$$
D V: 100 \times \frac{10}{\Delta t} \times \Delta \frac{A I(v 2) \text { hours worked by nativity group }}{\text { total hours worked }}
$$

\begin{tabular}{|c|c|c|c|c|c|c|}
\hline & \multicolumn{3}{|c|}{ Men } & \multicolumn{3}{|c|}{ Women } \\
\hline & Foreign-born & Native-born & All & Foreign-born & Native-born & All \\
\hline & $(1)$ & $(2)$ & (3) & (4) & (5) & (6) \\
\hline Immigrant shock (v2) & $\begin{array}{c}1.099 \\
(0.199)\end{array}$ & $\begin{array}{c}0.202 \\
(0.209)\end{array}$ & $\begin{array}{c}1.300 \\
(0.350)\end{array}$ & $\begin{array}{c}0.279 \\
(0.239)\end{array}$ & $\begin{array}{c}0.333 \\
(0.150)\end{array}$ & $\begin{array}{c}0.612 \\
(0.284)\end{array}$ \\
\hline State $\times$ Year FE & Yes & Yes & Yes & Yes & Yes & Yes \\
\hline Obs. & 1444 & 1444 & 1444 & 1438 & 1438 & 1438 \\
\hline Adj. R-squared & 0.566 & 0.398 & 0.375 & 0.429 & 0.371 & 0.362 \\
\hline DV Mean & 0.116 & 0.045 & 0.161 & 0.007 & -0.083 & -0.076 \\
\hline DV 25th percentile & 0.013 & -0.078 & 0.052 & -0.035 & -0.142 & -0.143 \\
\hline DV 75th percentile & 0.169 & 0.154 & 0.251 & 0.038 & -0.029 & -0.009 \\
\hline
\end{tabular}

The dependent variable is the change in the share of hours worked in AI-related occupations (V.2 definition) for stacked first differences over 2000-2009 and 2009-2018 for men (columns 1-3) and women (4-6), shown separately for all workers (columns 5 and 6), foreign-born workers (columns 1 and 2), and native-born workers (columns 3 and 4). The immigrant shock for AI-related occupations (V.2 definition) is defined in equation (2). The sample is individuals 25 to 54 years old with at least a bachelor's degree residing in one of the 722 commuting zones in the continental US. All regressions include a constant, the summed product of the weights used in the immigration shock, state fixed effects, and initial-period shares of the college educated in the population, the foreign-born in the population, females in total employment, employment in manufacturing, employment in routine-intensive jobs, and employment in offshorable jobs. Standard errors (in parentheses) are clustered by state. Regressions are weighted by $\mathrm{CZ}$ employment (of prime-age, college educated workers of the designated gender) in the initial period. 